\title{
LA OFERTA AL PUBLICO: RAZONES PARA UNA DISCREPANCIA
}

Hugo Forno Flórez

\section{INTRODUCCION}

El Código Civil peruano promulgado en 1984 regula por primera vez entre nosotros la oferta de contratar dirigida al público. El artículo 1388 cc. establece que: "La oferta al público vale como invitación a ofrecer, considerándose oferentes a quienes accedan a la invitación y destinatario al proponente. Si el proponente indica claramente que su propuesta tiene el carácter obligatorio de una oferta, valdrá como tal".

La primera observación que en seguida puede plantearse a este artículo es que a la oferta al público sólo le atribuye como una regla de carácter general el valor de una invitación a ofrecer, con lo cual se niega la posibilidad de que las ofertas que se hagan al público cumplan la función de una verdadera oferta. $O$ sea, se reconoce únicamente con perfiles de excepción que la oferta al público sí vale como tal, esto es, que puede cumplir la función que le corresponde de acuerdo con su naturaleza, pero sólo si se indica que la oferta al público tiene el carácter obligatorio (1) de una oferta y, además, si esto se indica claramente. Entonces, en el Perú la naturaleza jurídica de la oferta al público depende no sólo de que sea obligatoria sino de que esto se indique claramente.

A lo largo de estas líneas nos proponemos analizar la naturale-

(1) La oferta, en realidad, no puede ser obligatoria en el sentido de producir verdaderas obligaciones. Como se verá más adelante, cuando la ley se refiere a la "oferta obligatoria", hace alusión en verdad a la oferta irrevocable. 
za jurídica de la oferta al público y la problemática que en torno a ella se presenta a la luz de la doctrina contemporánea, sobre la base de la función que la práctica impone, con el afan de mostrar la necesidad de modificar el tratamiento legal de esta figura en una futura reforma. Para cumplir este propósito tendremos que recorrer, en primer lugar, la noción de oferta en general y sus requisitos; luego el carácter recepticio que, por lo general, tiene; más adelante nos ocuparemos de la invitación a ofrecer; $y$, finalmente, de la oferta al público propiamente dicha.

\section{LA OFERTA: NOCION Y REQUISITOS}

La oferta es una declaración que una o más partes hace a otra u otras, sometiendo a su consideración la celebración de un determinado contrato, en tal forma que para que éste se celebre sólo se requiere la aceptación del destinatario, sin necesidad de que se produzca una nueva declaración del oferente (2).

De esta noción se desprenden, como observa la mayor parte de la doctrina (3), que la oferta debe: a) ser completa o autosuficiente; b) emitirse con seria intención de contratar; y c) revestir eventualmente una forma específica.

a) Autosuficiencia de la oferta.

La propuesta tiene como función permitir la conclusión del contrato tan pronto como sea eficazmente aceptada por el (o los) destinatario(s) de la misma y es, por consiguiente, la última declara-

(2) Sustancialmente conforme: DE LA PUENTE, Estudios del Contrato Privado, Cultural Cuzco, Lima. 1983. T. I. p. 172. También OSTI, G., Scritti Giudirici, Giuffré. Milano. 1973. T. II. pag. 825-826. FERRI, L., Lezioni sul Contratto, sec. edizione. Zanichelli, Bologna. 1987, p. 67.

(3) CARRESI, F. Il Contratto. En: Trattato di Diritto Civile e Commerciale, giá diretto da Cicu e Missineo, continuato da Mengoni, Giuffré, Milano, 1987, V. XXI, T. 2, pp. 756 y sgtes.; OSTI, G., Op.Cit., pp. 826 y sgtes. 
ción del oferente que integra la estructura del contrato. La propuesta debe contemplar, pues, todos los elementos esenciales del contrato y aquellos otros que regularán la relación contractual si la aceptación se verifica, o la forma en que han de determinarse aquellos puntos que no han sido en ella contemplados.

Esta autosuficiencia no significa, sin embargo, como podría parecer a primera vista, que en la oferta deben agotarse todos y cada uno de los puntos sobre los que recaerá el consentimiento de las partes; significa, más bien, que la oferta debe ser suficiente para que, integrada con la aceptación y sin necesidad de un nuevo pronunciamiento del oferente, haya acuerdo en todos los puntos sobre los cuales el oferente ha considerado relevante pronunciarse.

Por eso no existe ningún inconveniente para que el oferente derive a la determinación del destinatario de la oferta, ciertos aspectos del programa contractual, sin importar que éstos sean elementos esenciales o cuestiones de orden secundario, con tal que de la oferta resulte con precisión cual es la naturaleza de aquéllos. Ahora bien, cuando se trata de un elemento esencial debe indicarse dentro de qué parámetros debe desenvolverse la determinación del destinatario de la oferta; o sea, debe establecerse ciertos límites que éste no puede sobrepasar al efectuar la determinación de tal elemento.

En este orden de ideas, puede, por ejemplo, deferirse al destinatario la determinación del precio siempre que sea claro que se trata de ese elemento (para permitir inferir que se propone una compra-venta) y no de otro, como podría ser un automóvil (lo que configuraría una permuta).

No es ocioso recalcar a este respecto, a propósito del ejemplo recién propuesto, que cuando se somete al destinatario la determinación de un elemento esencial del futuro contrato, deben establecerse también las fronteras dentro de las cuales puede fijarse dicho elemento. De no ser así se dejaría totalmente confiada a una de las partes la suerte del aspecto más importante del contenido del contrato. Si los lineamientos para la determinación del elemento esencial no son establecidos en la oferta, no existiría el requisito de la autosuficiencia y no podría dar lugar a la formación del contrato. 
Este principio ha sido recogido por el artículo $1543 \mathrm{cc}$, a propósito del contrato de compra-venta. Sin embargo, hubiera sido deseable una norma de carácter general. Ahora bien, una disposición como la que contiene el citado artículo parecería no admitir la posibilidad de que el precio fuera determinado por el destinatario ni siquiera en base a los parámetros establecidos por el oferente, pues su texto señala que "la compra-venta es nula cuando la determinación del precio se deja al arbitrio de una de las partes". Pero una interpretación en tal sentido no debe ser admitida, ya que no encuentra sustento ni lógico ni jurídico. Resulta significativo destacar que el tenor del precepto fue amputado por la Comisión Revisora del Código Civil. El texto propuesto por la Comisión encargada del Estudio y Revisión del Código Civil de 1936, rezaba: "La compraventa es nula cuando la determinación del precio se deja al solo arbitrio de una de las partes". La presencia del vocablo "solo" no era una mera casualidad que el legislador de la Comisión Reformadora introdujo sin querer y su supresión no es afortunada e induce a confusión, pues lo que no resulta aceptable es que un elemento esencial, como es el precio, pueda ser fijado libérrimamente por una de las partes con exclusión total de la otra, cosa que no ocurre cuando el oferente se encuentra conforme con que el precio -0 , en general, el elemento esencial de que se trate- sea determinado dentro de los parámetros que él ha fijado. Cuando el proponente ofrece en venta un inmueble al precio que determine el aceptante, entre US $\$ 90,000.00$ y US $\$ 100,000.00$, el precio, es cierto, es fijado por el destinatario, pero dentro del ámbito establecido por el oferente cuya declaración significa aceptar por anticipado la decisión del destinatario, siempre que se encuentre dentro de la gama de posibilidades establecidas en la oferta.

Esta aceptación anticipada del oferente impide que deba emitir un nuevo pronunciamiento frente a la declaración del aceptante.

La admisión del principio expuesto encuentra sustento, como afirma acertadamente De la Puente, en que la exigencia de que no se requiere nueva declaración del oferente no sólo se cumple cuando la aceptación constituye un simple "si", sino también cuando es deter- 
minado por el aceptante lo que estaba indeterminado, pero a su elección en la oferta (4).

La autosuficiencia de la oferta tampoco significa que ella debe agotar todos los extremos sobre los cuales la ilimitada imaginación del hombre podría sugerir un acuerdo. No compartimos, pues, la opinión de algún autor según la cual, en el ejemplo de quien propone a otro la venta de determinada cantidad de carbón a tal precio, manifestando que el producto está en Inglaterra, pero sin indicar lugar de entrega y quién correrá con los gastos de transporte, seguro y flete, estaríamos ante una oferta incompleta (5). La verdad es que tal propuesta es suficiente y, si fuera aceptada, formaría el contrato. En el ejemplo propuesto, el contrato debería ser integrado con las normas dispositivas previstas para el contrato celebrado. Si el Código Civil peruano fuera aplicable al caso, la solución a la omisión que contiene esa propuesta se encontraría en los arts. 1530 y 1535. Tal autor, sin embargo, no está en desacuerdo con el criterio expuesto cuando en otro lugar afirma que "ni todos los aspectos marginales del negocio jurídico propuesto deben estar necesariamente incluidos en la oferta contractual... Es suficiente que la oferta contenga las cláusulas significativas o puntos esenciales con arreglo a la clase general de los negocios de que se trate ..." (6).

Cuestión distinta es la relativa a la formación progresiva del contrato, o sea, a la formación del contrato mediante sucesivos acuerdos parciales entre las partes, o simplemente al caso en que la propuesta no recoge todos los aspectos respecto a los cuales las partes se han propuesto consentir, reservando algunos de ellos para posterior acuerdo. ¿Qué ocurre si una propuesta como esta es aceptada por el destinatario? Este es un problema que puede vincularse con el tema que se conoce con el nombre de Punktation, o puntualización o minuta, y que lamentablemente no podemos detenernos a analizar con detalle ahora. Sólo vamos a revisar muy escuetamente cómo se legisló este aspecto en el nuevo código.

(4) DE LA PUENTE, Manuel. Ob.Cit. T.I., p. 174.

(5) SPOTA, Alberto Gaspar, Instituciones de Derecho Civil: Contratos, Depalma, Buenos Aires, 1978. Vol. I. pp. 265-266.

(6) SPOTA, Ob.Cit, Vol. I, p. 266. 
En principio rige el criterio de la unidad del contrato, de tal manera que éste no puede formarse si las partes no convienen en todos sus extremos (art. 1359 CC.). Este criterio, sin embargo, parecería encontrar una excepción en el art. $1360 \mathrm{CC}$., que permite que el destinatario, al aceptar una propuesta con las características apuntadas, acuerde con su oferente relegar los puntos de que se trate para un acuerdo posterior. Lo que no resulta del todo claro es el efecto jurídico que produce en tal supuesto la aplicación de esta disposición. El tenor del art. 1360 (7) permite dudar del cabal sentido que debe atribuirse al precepto y autoriza a admitir con el apoyo de la exposición de motivos (8) al menos dos interpretaciones.

La primera interpretación posible consistiría en que la estipulación de un contrato en el que las partes deciden reservar algún aspecto para posterior acuerdo, lo hace válido y perfecto desde que se celebra y sólo su eficacia queda pendiente de que se satisfaga la reserva; o sea, el contrato ya celebrado no produciría efectos mientras los contratantes no decidan de común acuerdo el aspecto reservado. Esta parece ser la tesis que propugna el propio Arias-Schreiber (9), cuando indica que en tal hipótesis el contrato estará condicionado (suponemos que suspensivamente) a que con posterioridad dicha reserva se satisfaga $(10)$.

De admitirse como válida esta primera posible interpretación; la incertidumbre respecto al ulterior acuerdo produciría, como

(7) El art. 1360 CC. reza: "Es válido el contrato cuando las partes han resuelto reservar alguna estipulación, siempre que con posterioridad la reserva quede satisfecha, en cuyo caso opera retroactivamente.

(8) ARIAS-SCHREIBER, Max, En: Código Civil, VII: Exposición de Motivos y Comentarios, p. 23.

(9) Código Civil, Ob.cit., p. 23.

(10) Debemos aclarar, de paso, a propósito del texto citado en la nota anterior, que no se trata de un caso en que cualquiera de las partes se ha reservado una facultad o derecho como allí indica equivocadamente el codificador, sino del caso en que ambas resuelven que algún punto del esquema contractual será materia de un acuerdo posterior. 
sostiene algún autor (11), un conflicto entre dos exigencias merecedoras de tutela. De un lado, aquella de no sacrificar la libertad contractual, teniendo en consideración que las partes se han obligado a respetar un acuerdo que no está completo y que podría no llegar a estarlo nunca; $y$, de otro lado, aquella de tutelar la buena fe contractual contra la impugnación del contrato por una de las partes bajo el pretexto de que tal o cual punto, incluso poco importante, no ha sido todavía disciplinado.

Resulta evidente que de aceptarse la interpretación (del art. 1360 CC.) que ahora se analiza, que nosotros descartamos según tendremos ocasión de explicar más adelante, debe entenderse que los aspectos que el art. $1360 \mathrm{CC}$. permite reservar para un acuerdo futuro no pueden ser elementos esenciales del contrato. La razón es muy simple: si el contrato se forma y sólo su eficacia queda en suspenso por efecto de la condición suspensiva, es necesario que al menos existan los elementos esenciales. Arias-Schreiber, que según hemos dicho parece patrocinar esta primera tesis que venimos exponiendo, indica que la reserva puede referirse a cuestiones fundamentales como secundarias. Entendemos que cuando el Maestro Sanmarquino se refiere a "cuestiones fundamentales" (12), no pretende hacer mención a "elementos esenciales del contrato", sino tan sólo a aspectos de importancia; de otro modo no vemos cómo pueda formarse un contrato, aún sometido a condición suspensiva, sin que haya mediado acuerdo entre las partes respecto de uno de sus elementos esenciales.

La tesis que hasta ahora hemos desarrollado como posible interpretación del art. 1360, no parece ser la más apropiada. En primer término, habría que admitir que el evento condicionante de un contrato así formado sería el hecho de que las partes se pongan de acuerdo sobre la estipulación que decidieron reservar. Este evento no podría configurar una verdadera condición porque no reunirá los elementos que la caracterizan. Si bien futuro, el advenimiento del evento no sería incierto para las partes, ya que dependería absoluta-

(11) SCOGNAMIGLIO, Renato. En: Commentario del Codice Civile, a cura di Antonio Scialoja e Giuseppe Branca, Dei Contratti in Generale, Zanichelli, Bologna. 1970, p. 88-89.

ARIAS-SCHREIBER, Ob.Cit, T. I., p. 110. 
mente de la voluntad de cada una de ellas impedir que la condición se verifique; para ello les bastaría simplemente no consentir. En este caso no podría aplicarse siquiera el principio contemplado en el art. $176 \mathrm{CC}$., porque lo que se requiere es la estipulación de los elementos del contrato que han sido materia de la reserva. Hoy es unánime el rechazo de la doctrina a este tipo de condiciones denominadas meramente potestativas. Esto significaría, además, que las partes estarían vinculadas por un contrato ineficaz, cuya eficacia podría ser impedida unilateralmente por cada una de ellas, lo cual implicaria la inejecutabilidad del contrato. Aún más, esta situación anómala podría perpetuarse desde que la ley no ha previsto un plazo o un mecanismo para satisfacer la reserva hecha por las partes.

Pero, además, el propio texto del art. 1360 no se condice con una interpretación de esta naturaleza y sugiere como correcta la segunda posible interpretación. En realidad, el precepto supedita la validez y no la eficacia del contrato a la consecución del acuerdo posterior, de manera que el contrato no es válido mientras no se haya satisfecho la reserva. El art. 1360 indica, en efecto, que "Es válido el contrato ... siempre que ...". La expresión "siempre que", determina que la validez sólo se da cuando se satisface la reserva. Podría pensarse, entonces, que se trata de un contrato inválido pero existente, o sea, que el contrato se forma pero defectuosamente. Esta tesis no puede sostenerse porque el artículo en estudio está regulando la formación del contrato y, por ende, su existencia. Ocurre que nuestro Código Civil, al menos en la parte relativa a los contratos en general, ha sido muy poco riguroso al emplear los conceptos "existencia", "validez" y "eficacia". Es evidente que tal como lo hace el art. 1359, el art. 1360 debe entenderse referido a la existencia del contrato. Ahora bien, esto quiere decir que el contrato no se forma en el momento en que se estipula la reserva, ya que, eventualmente, sólo se formará en el futuro, cuando aquella se haya satisfecho. Si, como nosotros pensamos, este es el correcto sentido que tiene el artículo 1360 , los detractores de esta opinión podrían preguntarse cuál es entonces la diferencia entre esta disposición y la del art. 1359. La diferencia más importante es la que consiste en el efecto retroactivo que concede al contrato el art. 1360, en el sentido que se entiende perfeccionado en la fecha en que se efectuó la reserva, cosa que no ocurre en el caso del art. 1359, según el cual el contrato sólo se entenderá formado en la fecha en que se convenga sobre el último punto del programa contrac- 
tual. Es evidente que como la retroactividad que la ley contempla puede resultar inconveniente; hubiera sido deseable que se permitiera a las partes estipularla en lugar de establecerla como un efecto natural.

\section{b) Intención seria de contratar}

La oferta está destinada a formar el contrato si la aceptación se produce. Para ello, quien la formula debe hacerlo con el propósito de quedar vinculado por el contrato si la simple aceptación del destinatario tiene lugar. Dicho en otros términos, la oferta debe comportar una efectiva intencićn de formar el contrato. En tal sentido, Miccio (13) tiene razón cuando alega que el intérprete debe asegurarse que la declaración no contiene una simple enunciación de un propósito (no definitivo aún), o un mero deseo de contratar, de tal naturaleza que permitan suponer razonablemente que todavía se encuentra vigente el período de los tratos preliminares.

De esto se sigue que no son verdaderas ofertas las que se hacen en broma o en representaciones teatrales o a título ejemplificativo, etc., a las que en general se conoce como ofertas no serias. Pero la objetividad que rodea la cuestión de decidir si una oferta concreta es o no seria, no debe conducir al extremo de entender que la oferta no es tal únicamente porque el proponente declara que formuló una oferta no seria. La falta de seriedad de la oferta debe resultar claramente de los propios términos de ella o de las circunstancias del caso.

Un supuesto de duda lo suscita el problema relativo a la relevancia que merece una oferta que se formula con el convencimiento de que no será aceptada. Se observa, a este respecto, que tal apreciación no es más que una opinión del proponente que no puede afectar la verdadera naturaleza de la oferta. Scognamiglio parece compartir esta tesis (14). Sostiene que debe tenerse en cuenta, desde el punto de vista de la confianza del destinatario, que la propuesta se dirige específicamente a suscitar la adhesión del destinatario y, por otro lado, siempre puede ser revocada antes de la aceptación (a

(13) I Diritti di Credito, UTET, Torino, 1977, Vol. II, T. 2, p. 132.

(14) SCOGNAMIGLIO, Renato. Dei Contratti... Ob.Cit., p. 90. 
diferencia del Código italiano, en nuestro código sólo se permite la revocación si el proponente se ha reservado tal facultad en la oferta; o después, si lo ha hecho saber al destinatario al menos al momento en que éste conoce la oferta; o si la naturaleza de la operación o las circunstancias del caso determinan su revocabilidad: art. 1382 y 1384). Ocurre que, como ya se ha puesto de manifiesto, la falta de seriedad de la propuesta debe resultar con claridad de las circunstancias que rodean a su formulación o de los propios términos de ésta, y, lo que es más importante, la falta de seriedad en base a dichas circunstancias debe ser conocible para el destinatario de modo que éste no pueda razonablemente confiar en la seriedad de la misma, ya que en caso contrario sí habrá que tutelar la confianza del destinatario. Miccio (15) proporciona el ejemplo del propietario de un yate que cuesta cientos de millones y que lo ofrece en venta a un pobre marinero que concurre a limpiar el alcázar o a realizar otros humildes servicios. ¿Cómo excluir — se pregunta - que se trata de una oferta no seria?

La mayor parte de la doctrina coincide en incluir dentro de las ofertas no serias aquellas llamadas "ofertas sin compromiso" (16). Son las que el proponente formula sin el ánimo de quedar vinculado si recae la aceptación del destinatario, y suelen incluir frases o cláusulas como "sin compromiso","salvo confirmación" u otras análogas.

Para Scognamiglio la propuesta sin compromiso no pierde su carácter de oferta, la cual, en su opinión, subsiste como acto idóneo para constituir el contrato. Según este autor, la propuesta así formulada sirve para conceder al oferente la facultad de sustraerse a los efectos de la aceptación. Nosotros no compartimos esta opinión ya que, como se ha expuesto, la oferta es la última declaración del

(15) Ob.Cit. Vol. II, T. 2, p. 132.

(16) COSSIO, Alfonso. Instituciones de Derecho Civil. Alianza Universitaria. Madrid, 1977. T. I., p. 258-259. VON TUHR, Andreas. Tratado de las Obligaciones. Editorial Reus, traducido por W. Roces. Madrid, 1934. T. I., p. 137-138. DE LA PUENTE, Manuel. Ob.Cit. T. I., p. 214. PUIG BRUTAU, José. Fundamentos de Derecho Civil. Bosch. Barcelona. T. II, Vol. I, 1978, p. 186. 
proponente, de modo que no requiere una nueva declaración de éste para que el contrato se forme una vez que sea aceptada. En la oferta sin compromiso, para que se forme el contrato siempre se requiere una nueva declaración de quien la hace.

Pero es interesante distinguir a este punto dos tipos de ofertas sin compromiso a las que se debe atribuir distinta naturaleza. De un lado, están las que menciona De la Puente (17), que consisten en la facultad que se reserva el proponente de modificar sus términos. A este tipo de declaraciones no puede atribuírsele, siquiera, la naturaleza de invitaciones a ofrecer, pues el oferente no se va a convertir en aceptante al fijar, por ejemplo, un nuevo precio. De otro lado, se encuentran aquellas propuestas que llevan la cláusula "sin compro. miso" u otras de efecto equivalente, en las que el proponente sólo se reserva el derecho de rechazar la aceptación y que son a las que Scognamiglio se refiere. Consideramos, con Tuhr (18), que este último tipo de ofertas, cada día más frecuentes en la práctica mercantil, no implican verdaderamente una oferta sino una invitación al destinatario para formular una propuesta que puede, a su vez, rechazarse o aceptarse. En este caso, si el destinatario acepta la invitación y formula la oferta (que paradójicamente tendrá apariencia de aceptación), el proponente original deberá rechazarla prontamente si no la encuentra conforme, pues su silencio tendrá el significado de aceptación por el principio que informa el art. $1381 \mathrm{CC}$., en concordancia con el art. 142 CC.

\section{c) Forma de la oferta}

Rige en principio para la oferta, como rige en general para las declaraciones de voluntad, la libertad de forma que consagra el artículo 143 de nuestro Código, de modo que el declarante puede formular la oferta utilizando la forma que considere más adecuada a los fines de poner en conocimiento del destinatario el contenido de su propuesta.

(II)

Ob.Git. Vol. ., p.214.

ob.Cit. Vol. I, p. 138. 
Se ha sostenido en la doctrina, con indudable rigor lógico (19), que, atendiendo a la función de la propuesta, el problema relativo a su forma resulta absorbido por el problema más general concerniente a la forma del contrato. Por ello, no resulta inútil preguntarse si acaso las ofertas de contratos solemnes por imperio de la ley o por voluntad de las partes deben revestir la misma forma establecida para el contrato. Algún autor nacional ha respondido negativamente a la cuestión planteada, sosteniendo tajantemente que "... en el caso de los contratos en los que la ley exige el cumplimiento de una forma determinada bajo sanción de nulidad o en los que las partes han convenido en una especial (art. 1411) tanto la oferta como la aceptación podrán revestir cualquier forma, pero el contrato no se entenderá concluido sino a partir del momento en que se cumpla la solemnidad exigida por la ley o impuesta por las partes" (20). Esta afirmación podría considerarse respaldada por el art. $1352 \mathrm{CC}$. que parece hacer de la forma un requisito independiente del consentimiento; no obstante, no parece que pueda ser compartida.

Los autores que se ocupan del particular coinciden casi unánimemente en que, estando destinada la oferta a concluir un contrato solemne, no puede aquélla no ser subordinada a la misma forma impuesta con tal carácter para el contrato que se propone (21). La forma, en realidad, es el mecanismo o instrumento que se utiliza para exteriorizar la voluntad, y en los contratos solemnes la declaración de voluntad se debe realizar necesariamente en la forma prescri-

(19) SCOGNAMIGLIO, Dei Contratti ..., Ob.Cit., p. 91.

(20) ARIAS-SCHREIBER, Max. Exégesis. Studium. Lima, 1986. T. I., Contratos: Parte General, p. 130.

(21) FERRI, Luigi. Ob.Cit., p. 70. ALBALADEJO, M. Curso de Derecho

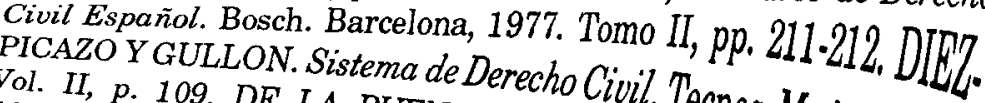
PICAZO Y GULLON. Sistema de Derecho Civil. Tecnos. Madidi, 1985.
Vol. II, p. 109. DE LA PUENTE, Manuel. Ob.Cit., T. I, p. 182.
FONTANARROSA, R. Derecho Comercial Argentino. Victor
Zavalia. Buenos Aires, 1979. T. II: Doctrina Gen Comerciales, p. Aires, 1979. T. II: Doctrina Argentino. V. Vi, p. 182.
BIANCA, Massim. SCOGNAMIGLIO

1984. Vol. III: II Co. Diritto Civile. Dot Dei Contratti... Ob. Contratos 
ta, de modo que el derecho sólo considera existente la declaración cuando ésta adopta la forma exigida. Si se considera que, como se admite ampliamente, la oferta (como la aceptación) es una de las declaraciones contractuales, es decir, una de las declaraciones de voluntad que configuran el contrato, no se puede sostener, como lo hace Arias-Schreiber, que en los contratos solemnes la oferta y la aceptación pueden realizarse en cualquier forma que los interesados deseen.

Si la oferta de un contrato formal se hace en forma distinta a la requerida por la ley, deberá considerarse que no existe oferta de tal contrato (21a). Ni siquiera puede considerarse que se trata de oferta de un contrato preliminar, ya que el contrato preliminar de un contrato formal es, de reflejo, contrato preliminar formal (art. 1425 $\mathrm{CC}$ ). Si el proponente y el destinatario no cumplen al declarar la oferta y la aceptación con la formalidad exigida ab substantiam y luego, como sugiere Arias-Schreiber, se cumple la solemnidad otorgando, por ejemplo, la escritura pública correspondiente, deberá entenderse que sólo entonces se está formulando contextualmente la oferta y la aceptación con arreglo a ley.

La solemnidad es, en efecto, una carga (22) impuesta a los declarantes, de modo que la ley sólo considera que la declaración de voluntad existe si se cumple, precisamente, con adoptar la forma exigida para la exteriorización de esa voluntad.

Resulta importante destacar igualmente que la propuesta, atendiendo a su finalidad y requisitos, sólo puede formularse, por lo general, de manera explícita; únicamente por excepción puede la oferta realizarse tácitamente, o sea, con los medios que hagan evi-

(21a) Véase STOLFI, Giuseppe. Teoría del Negocio Jurídico. Editorial Revista de Derecho Privado. Madrid, 1959, p. 17-18. El sostiene, con razón, que la forma en estos casos más que un elemento autónomo del contrato viene a ser un requisito del consentimiento.

(22) MESSINEO, Francesco. Manual de Derecho Civil y Comercial. Trad. Santiago Sentis Melendo. Ediciones Jurídicas Europa-América. Buenos Aires, 1979. T. I, p. 85. 
dente para la otra parte la intención de celebrar un determinado contrato. El ejemplo que se suele dar para este supuesto excepcional es el de la oferta de venta realizada mediante aparatos automáticos (23). No podemos dejar de observar, no obstante, que la naturaleza de verdadera oferta y de contrato como resultado de la utilización de un aparato automático, es todavía materia de un intenso y extedido debate en la doctrina. Es también un supuesto de aceptación tácita el contemplado por el art. $1380 \mathrm{CC}$.

\section{EL CARACTER RECEPTICIO DE LA OFERTA}

La oferta es por lo general una declaración contractual de las conocidas modernamente como declaraciones recepticias. La creación de este término se atribuye a Zitelmann (24) y a pesar de la viva atención que logró despertar entre los estudiosos, no está todavía nítidamente perfilado en la doctrina.

\section{a) Manifestación y declaración}

$\mathrm{Ni}$ siquiera el concepto de declaración -en el que habremos de detenernos momentáneamente como punto de partida del tema que hemos abordado- y el de manifestación son unánimemente compartidos por los autores. La manifestación, observa Stolfi (25), es designada más propiamente declaración cuando no es perfecta hasta que no es cotejada con otra persona. Así, mediante el testamento el testador manifiesta su voluntad de disponer de su patrimonio, ya que el acto mortis causa para considerarse perfecto no es necesario que

(23) SCOGNAMIGLIO, R. Dei Contratti... Ob.Cit., p. 91.

(24) MIRABELli, G. Dei Contratti in Generale. En: Commentario del Codice Civile. Libro IV, Tomo Secondo. UTET. Torino, 1980, p. 96. SPOTA, A. Instituciones de Derecho Civil, Contratos. Vol. I. Depalma, Buenos Aires, 1978, p. 261. PUIG PEÑA, F. Tratado de Derecho Civil Español. T. I, Vol. II. Editorial Revista de Derecho Privado. Madrid,
1958, p. 500.

(25) Ob.Cit., p. 6. 
llegue a conocimiento de otras personas y, por el contrario, se dice que los contratantes declaran su voluntad propia porque el contrato supone que cada uno de ellos manifiesta su intención a la otra parte. Puede apreciarse cómo el elemento diferenciador entre manifestación y declaración es situado por Stolfi en el hecho de que la segunda, y no la primera, se perfecciona sólo cuando es conocida por otra persona por estar dirigida a ella.

Otros autores (26) no encuentran diferencia y utilizan en forma promiscua ambos términos.

Sin embargo, existen conductas que revelan una voluntad de su autor y que por naturaleza son distintas tanto de los actos que Stolfi denomina manifestaciones de voluntad, como de los que él llama declaraciones de voluntad. En atención a ello, una autorizada corriente de opinión (27) que se ha ocupado de estudiar el tema muy acuciosamente, ha encontrato entre manifestación y declaración una diferencia de género a especie. La manifestación de voluntad consiste en un hecho o en una conducta del sujeto, realizados de manera consciente y voluntaria, a través del cual se revela una determinación volitiva, ya sea que la intención del agente haya sido o no, transmitir directamente a otros su voluntad.

Dentro de este genérico concepto de manifestación, cuando el propósito que anima al sujeto a realizar esa conducta es precisamente el comunicar a otros su voluntad, y esa conducta consiste en un medio idóneo para tal fin, entonces a este tipo de manifestación se le denomina específicamente declaración. En cambio, cuando una conducta no tiene el propósito directo de transmitir a otro una voluntad, pero ésta se revela indubitablemente, a esa conducta se le llama manifestación (en sentido estricto).

(26) CASTAN, J. Derecho Civil Español, Común y Foral. Reus S.A. Madrid, 1982. T. I, Vol. 2, pp. 741-742.

(27) LOHMAN, J. El Negocio Jurídico. Studium. Lima, 1986, p. 80. SCOGNAMIGLIO, R. Dei Contratti... Ob.Cit., pp. 170-171. BIANCA, M. Ob.Cit., pp. 212-213. DIEZ-PICAZO Y GULLON. Ob.Cit., p. 509. MESSINEO, F. Manual... Ob.Cit., pp. 332-333; ver también p. 361. 
En palabras de Sacco (28), la declaración es presentada como una subcategoría de la manifestación. Esta última puede ser directa (la intención se deduce de un comportamiento que según la común experiencia está destinado a hacerlo socialmente reconocible) 0 indirecta (la intención se deduce por hilación necesaria y unívoca de un comportamiento concluyente que no tiene la destinación ya descrita); o sea, la manifestación puede desarrollarse mediante un lenguaje (medios simbólicos de significado, o sea, signos fonéticos, gráficos, etc.) o mediante un comportamiento práctico que tiene una finalidad unívoca. La manifestación que se desarrolla mediante un lenguaje es declaración.

En este orden de ideas, la manifestación en su sentido más lato puede sub-clasificarse en: a) Manifestación en sentido estricto y b) Declaración.

Desde esta perspectiva, que juzgamos acertada, la diferencia entre ambos conceptos estriba en que la manifestación en sentido estricto consiste en una conducta que el sujeto realiza pero no con el propósito de comunicar su voluntad a otros, sino de obtener un resultado práctico inmediato (como por ejemplo el caso de la aprehensión, art. 929 CC.), aun cuando de tal conducta se revela indirectamente, o sin querer, la voluntad del sujeto (o sea, en el ejemplo propuesto, la de apropiarse del bien). En la declaración, en cambio, lo que el sujeto se propone es comunicar a otros su voluntad, de modo que la exteriorización de ella no resulta una consecuencia accidental del acto sino que constituye su razón determinante; y por ello, el medio utilizado con tal propósito debe ser, en el ambiente social de que se trate, idóneo para hacer conocible a los demás la voluntad que se revela (28bis.).

(28) En Trattato Di Diritto Privato, Diretto da Pietro Rescigno. UTET. Torino, 1983. Vol. 10, Tomo Secondo, pp. 49-50. Ver también BARASSI, Lodovico. La Teoría Generale delle Obbligazioni. Giuffré. Milano, 1964. Vol. II. Le Fonti, p. 109.

(28bis.) Esta teoría es también sustentada con particular claridad aunque con algunas peculiaridades por VON THUR, Andreas. Tratado de las Obligaciones, traducido por W. Roces. Primera Edición. Editorial Reus. Madrid, 1934. Tomo I, p. 115. 
En otras palabras, mediante la declaración el sujeto intenta producir un efecto psíquico en otros, efecto que consiste en la representación mental de su interno querer. Mediante la manifestación en sentido estricto el sujeto sólo realiza el acto con la intención de producir un efecto material inmediato. De ahí que a diferencia de la manifestación en sentido estricto, en la declaración se presenta, además de la voluntad que se revela y que es, por ello, objeto de la declaración (que la doctrina denomina voluntad declarada), la voluntad de revelar el querer interno comunicándolo a otros (que la doctrina llama voluntad de declarar) (29).

Los diversos anteproyectos y proyectos preparados en el seno de la Comisión encargada del Estudio y Revisión del Código Civil de 1936, no trataron el tema de un modo técnico y usaron ambas expresiones en forma indistinta. Cabe destacar, sin embargo, que para Susana Zusman y para Manuel de la Puente, autores de uno de los anteproyectos, el tema no fue ajeno y conscientemente emplearon el término declaración en un sentido lato, no técnico, como sinónimo de manifestación.

Ello se deduce con facilidad de la exposición de motivos que sustenta su anteproyecto, en donde escriben: "Dado que la voluntad del agente puede exteriorizarse no solamente mediante declaraciones, entendidas éstas en un sentido estricto, sino también mediante comportamientos, se define el acto jurídico como una declaración de voluntad, entendiendo que este término comprende tanto las palabras o signos como cualquier otra forma ce expresión, manifestación y comunicación de la voluntad, o sea, lo que se conoce como conducta expresiva (30).

Sin embargo, según parece, por obra de la Comisión Revisora la manifestación de voluntad es concebida por nuestro Código desde

(29) ALBALADEJO, M. El Negocio Jurídico. Bosch. Barcelona, 1958, pp. 79-80.

(30) ZUSMAN, S. y DE LA PUENTE, M.Anteproyecto Sustitutorio de los Actos Jurídicos, Proyectos y Anteproyectos de la Reforma del Código Civil. Pontificia Universidad Católica del Perú. Fondo Editorial. Lima, 1980. Tomo II, p. 45. 
el punto de vista genérico que hemos indicado líneas arriba y adopta, en nuestra opinión, la diferencia de género a especie con relación a la declaración en los términos ya explicados. En efecto, el art. 141 indica que la manifestación de voluntad puede ser expresa o tácita. Es expresa - agrega - cuando se formula oralmente, por escrito, o por cualquier otro medio directo. Es tácita cuando la voluntad se infiere indubitablemente de una actitud o de circunstancias de comportamiento que revelan su existencia. Hasta aquí el Código ha definido la manifestación en términos genéricos.

Pero, a continuación, en su segundo párrafo, el mismo artículo señala que no puede considerarse que existe manifestación tácita cuando la ley exige declaración expresa o cuando el agente formula reserva o declaración en contrario. Es muy sintomático que el Código haya utilizado la palabra manifestación al momento en que ya en términos específicos se ha querido referir a la exteriorización tácita, y, en cambio, a renglón seguido, dentro de la misma oración, utilice la palabra declaración cuando se refiere a la expresa. Y es que, como pone de manifiesto Scognamiglio, de declaraciones (en sentido técnico) sólo puede hablarse cuando se trata de declaraciones expresas, las que, según este autor, implican "... como se suele decir, un hecho de lenguaje, o en otros términos la adopción de medios expresivos, reputados en un cierto ambiente idóneos para revelar un determinado significado; y se configuran según las exigencias y para el fin de conducir un cierto objeto en ellos contemplado -que puede ser más que una regla negocial, y es la hipótesis ya considerada, el resultado de un juicio o la noticia de un hecho- a conocimiento de otro" (31).

Sólo de las declaraciones en el sentido técnico ya descrito, puede decirse que son recepticias o no recepticias. Esta clasificación no es posible encontrarla en el ámbito de las manifestaciones de voluntad en sentido estricto (32).

(31) SCOGNAMIGLIO, R. Dei Contratti... Ob.Cit., p. 171.

(32) SACCO, R. Ob.Cit., p. 50. 


\section{b) Declaración recepticia}

El término "recepticio" (emfangsbiduritg) parece hacer alusión a la necesidad de recepción por parte de otro. Así, la declaración recepticia sería la declaración de voluntad que debe ser recibida por otro. Sin embargo, se observa que para que una declaración sea recibida por otro, tiene que ser previamente dirigida por el emitente a aquél que debe recibirla. Declaración recepticia sería entonces aquella que es dirigida a otro. Pero si tenemos en consideración que declaración es sinónimo de comunicación y que toda declaración en sentido técnico implica una voluntad de declarar y, por lo tanto, un dirigir esa declaración a quien quiera que deba comunicársele, entonces la clasificación de declaraciones recepticias y no recepticias sería superflua, pues resultaría absorbida por la clasificación de manifestación y declaración tal como la entiende Stolfi, con las críticas que ya se han apuntado.

En cambio, la bipartición de las declaraciones en recepticias y no recepticias adquiere singular relevancia si se toma en consideración que existen declaraciones en las cuales se encuentra interesado un específico y determinado destinatario y que, por lo tanto, es él y sólo él a quien debe dirigirse y quien debe recibir esa declaración, porque por un interés que la ley tutela, sólo frente a él adquiere trascendencia jurídica dicha declaración. Estas son las declaraciones que la doctrina denomina recepticias. Son las más numerosas e importantes, como, por ejemplo, la oferta de contratar, la aceptación, las declaraciones que se indican en los artículos 1429, 1430, 1458, 1474 , etc.

Otras declaraciones no se dirigen ni deben ser conocidas necesariamente por un destinatario determinado, sino por todos, por cualquiera o por un grupo indeterminado de sujetos. En estos casos, como es obvio, la ley no considera existente un interés que determine que esa declaración sólo adquiera relevancia jurídica cuando sea cotejada con un sujeto previamente determinado. Estas declaraciones se denominan no recepticias y son las menos frecuentes, como, por ejemplo, la promesa al público, la invitación (al público) a ofrecer, el testamento, etc.

Ahora bien, si consideramos que toda declaración es por 
naturaleza una comunicación, o sea un hacer conocer algo a alguien, hemos de encontrar que en todo proceso declarativo existen cuatro fases teóricamente diferenciables, a saber: la emisión, la expedición, la recepción y el conocimiento. Por ello es preciso establecer en qué momento o fase se forma la declaración y a partir de qué momento produce consecuencias jurídicas. En las declaraciones realizadas entre presentes, modernamente denominadas declaraciones no incorporadas (33) (como en el caso de una declaración oral), la emisión se confunde con la expedición y la recepción con el conocimiento. Por otra parte, también en las declaraciones no incorporadas, la fase de la expedición y la de la recepción se suceden sin solución de continuidad, lo cual no dá lugar a mayores inconvenientes; lo importante es, pues, analizar este tema a propósito de las declaraciones incorporadas (34).

De las etapas que hemos mencionado, es incuestionable que la primera - la de la emisión- es absolutamente necesaria para la formación de toda declaración, desde que constituye el punto inicial en el que el autor hace exterior su voluntad interna, aquella que pretende comunicar, fijando de tal manera el contenido de la declaración. No parece que pueda concebirse la existencia de una declaración no emitida. Pero aun habiéndose producido la emisión, esta primera fase no es por sí sola suficiente para que quede formada la declaración. No puede decirse que formula una declaración perfecta quien hace un discurso a las estrellas o quien redacta una carta para depositarla en un cajón (35).

La fase de la expedición es también relevante a los efectos de que quede formada la declaración, en cuanto tiene el rol de transmitir su contenido de manera que en esta etapa el declarante se desprende de la declaración haciéndola accesible al destinatario. Un

(33) SACCO, R. Ob.Cit. p. 72.

(34) Nótese que el mismo problema se presenta y se discute, aunque con algunos ingredientes más, a propósito de la celebración del contrato entre no presentes, ya que éste se forma en virtud de dos declaraciones (la propuesta y la aceptación) incorporadas.

SCOGNAMIGLIO, R. Dei Contratti... Ob.Cit., p. 171. 
sector de opinión muy autorizada (36) enseña que ésta es la fase con la cual culmina el proceso de formación de la declaración porque es el momento en que su autor adopta los instrumentos necesarios, imprimiendo una dirección a su declaración, que marca la salida del acto de la esfera del declarante, haciendo posible que los interesados accedan a ella. Cumplida esta etapa, nada más tiene que hacer el declarante; la declaración se ha formado.

La expedición de la declaración es un acto voluntario del declarante, tan voluntario como la fase de emisión que le precede. Teóricamente, una declaración recibida o conocida sin que haya sido expedida por su autor no puede tener existencia jurídica. Imaginemos un caso hipotético en el cual una persona redacta y suscribe una carta proponiendo a otro la celebración de un contrato, pero no se decide todavia a expedirla a su potencial destinatario, quien casualmente de visita en casa del emitente la encuentra, se la lleva y toma conocimiento de ella. No podría, luego, el destinatario sostener la existencia jurídica de semejante propuesta.

Ya Jorge Giorgi (37) explicaba a principios del siglo, que si Ticio manifiesta a Sempronio su voluntad de vender a Cayo, sin darle ningún encargo de hablar a éste, Cayo no tiene derecho de tomar esta palabra, porque Ticio puede rechazarle diciendo: todavía no me he decidido, aún no he hablado contigo, tenía un propósito incierto que he abandonado.

No obstante lo hasta aquí expresado a propósito de la voluntariedad del acto de expedición de la declaración, no puede ocultarse el grave problema que en la práctica puede frecuentemente presentarse en situaciones de declaraciones recibidas por el supuesto destinatario, pero expedidas por circunstancias ajenas a la voluntad del emitente. Sacco (38) nos plantea el caso del empresario que dicta y

(36) BIANCA, M. Il Contratto..., Ob.Cit., p. 171.

(37) Teoria de las Obligaciones en el Derecho Moderno. Madrid, 1910. Vol. III, p. 204.

(38) En: Tratatto di Diritto Privato. Diretto de Pietro Rescigno. UTET. Torino, 1983. Vol. 10, p. 68. 
suscribe una propuesta y luego ordena a su secretaria que la destruya, orden que no es cumplida por ella y posteriormente la carta resulta expedida por un error del mensajero.

Si llevamos al extremo el elemento de la voluntariedad del acto de expedición de toda declaración, al punto de considerar, como en teoría debería ser, que toda y cualquier declaración recibida por su potencial destinatario, pero no expedida por el autor, carece por ello de existencia jurídica, resultaría desprotegido y acaso seriamente perjudicado ese seudo destinatario que confió de buena fe en la declaración, ignorando que no le fue voluntariamente expedida (39).

A fin de compatibilizar la naturaleza de las instituciones y la seguridad jurídica que el tráfico reclama, es imprescindible encontrar un punto de equilibrio que permita dirimir satisfactoriamente este conflicto que puede presentarse con frecuencia entre quien emite una declaración y quien la recibe (40). El conflicto se presenta entre el interés del emitente de no considerar existente una declaración que él no ha expedido voluntariamente, $\mathrm{y}$ el interés del supuesto destinatario de considerar no sólo existente sino también válida la declaración recibida por él y en la cual confió de buena fe. Estimamos que para solucionar prudentemente este conflicto de intereses nos pueden ser de utilidad las teorías de la responsabilidad y de la confianza (40a). La declaración no puede en ningún caso tener relevancia cuando no ha sido expedida por su autor, a no ser que la expedición se haya debido a una causa que se encuentre dentro de su esfera de actuación, o sea, en definitiva, por una causa que puede serle atribuible de modo que, por excepción, en base a la teoría de la responsabilidad, esa declaración podría, no obstante, producir conse-

(39) Debe observarse que en el ejemplo transcrito no sería aplicable la solución prevista en la parte final del art. $208 \mathrm{CC}$., por cuanto no existe error en la declaración, ni siquiera existe encargo de transmitir una declaración.

(40) SACCO, R., Ob.Cit., p. 68.

(40a.)La Teoría de la Confianza, por otro lado, es la que se ha adoptado en nuestro Código para resolver los problemas de error vicio y error obstativo. 
cuencias jurídicas. Pero aun en este caso, esa declaración no podría considerarse como una declaración perfecta si el que la recibió no podría haber confiado en ella de buena fe, al punto de tener que proteger su expectativa en base a la teoría de la confianza. En conclusión, una declaración no expedida voluntariamente por su autor sólo puede tutelarse si el acto de la expedición puede serle atribuible y siempre que quien la recibió haya confiado en la declaración, de buena fe.

Después de las consideraciones que hemos dejado anotadas, podemos concluir que toda declaración se forma mediante los actos de emisión y de expedición. Entonces, ¿qué rol desempeñan en la declaración las fases de la recepción y el conocimiento? Esto, como veremos en seguida, depende justamente del tipo de declaración de que se trate.

Ya se ha anticipado que la declaración recepticia es aquella que se dirige a una persona determinada porque interesa frente a ella en particular. Por eso hay algunos autores que sostienen que la declaración recepticia no se forma como tal, no tiene existencia, en tanto no haya llegado a conocimiento del destinatario, de suerte que la etapa del conocimiento formaría parte de la estructura de la declaración. Barassi comenta que en las declaraciones recepticias la percepción que de ellas tiene el destinatario es de tal importancia que entra en el conjunto de la declaración, y es un elemento de ella. Para Barassi es de tal importancia el conocimiento por parte del destinatario que también éste participa, por ello, en la formación de la declaración de voluntad recepticia (41).

No puede dudarse que en la declaración recepticia la etapa del conocimiento es también de importancia meridiana, ya que no existe en realidad comunicación alguna si el destinatario no conoce la declaración, o sea, si no se produce en el destinatario el evento psíquico que constituye la finalidad de la declaración, la representación mental del contenido de la declaración. Es por eso que Barassi

(41) BARASSI, L. Teoría Generale delle Obbligazioni. Vol. II. Dott A. Giuffré, Editore. Milano, 1964, p. 100. Este criterio también parece compartirlo DE LA PUENTE, M. En: Estudios sobre el Contrato Privado, Cultural Cuzco. Lima, 1983. T. I, p. 182. 
pretende que el conocimiento por parte del destinatario es también, al igual que la expedición, un elemento de formación (o constitutivo, como dice el autor) de la declaración. Probablemente en consideración a que el conocimiento o percepción de un hecho o de una idea implica una actitud y una conducta del sujeto, ha llegado a sostener Barassi que "... se puede entender que también el destinatario participa de la formación de la declaración de voluntad" (42).

Semejante acerto implicaría que todas las declaraciones recepticias son actos bilaterales, o sea, actos para cuya formación se requiere la intervención de dos sujetos, a saber: el declarante y el destinatario.

Más adecuada nos parece la opinión según la cual la formación de la declaración recepticia se agota en la etapa de la expedición, según hemos tenido ocasión de exponer. Pero estas declaraciones, a diferencia de las no recepticias, carecen de sentido si no son cotejadas especificamente con su destinatario, de suerte que el conocimiento de este último es un dato importante respecto a la función de la declaración recepticia y no respecto a su estructura. Por ello, el conocimiento por parte del destinatario es un requisito de eficacia, lo cual significa que la declaración ya formada al ser expedida sólo produce efectos desde que llega a conocimiento del destinatario. Quienes como Giampicolo suscriben esta tendencia, sostienen que la declaración existe desde que se expide, pues desde tal momento se verifican algunos efectos intermedios, si bien limitados a la esfera del declarante, pero hasta el momento del conocimiento la declaración no realiza su efecto final, aquél que más cuenta, no produce ninguna consecuencia jurídica, ni siquiera preliminar, frente al destinatario. De modo que, según ellos, este evento (el conocimiento) debe entenderse como un elemento constitutivo del efecto, o, mejor dicho, un co-elemento de la relevancia jurídica de la declaración frente al tercero (43).

Ahora bien, como el conocimiento es un evento voluntario que requiere inexorablemente la cooperación del destinatario, y como la fase que puede constatarse exteriormente con facilidad es la

(42) BARASSI, L. Ob.Cit., p. 100.

(43) SCOGNAMIGLIO, R. Dei Contratti.., Ob.Cit.., p. 175. 
de la recepción más que la del conocimiento, con el único propósito de facilitar la constatación del hecho y evitar que el destinatario se sustraiga a los efectos que la declaración habrá de producir, con el fácil expediente de no tomar conocimiento de ella, las legislaciones modernas, empezando por la italiana, han comenzado a establecer la presunción del conocimiento por parte del destinatario cuando se haya producido la recepción.

El Código Civil italiano en su art. 1334 sanciona que la eficacia de las declaraciones recepticias se produce con el conocimiento por parte del destinatario. Esto resulta no sólo del tenor del artículo sino del epigrafe que le precede. De allí se deduce, pues, que el legislador de Italia parece haber adoptado la tesis ya expuesta según la cual la declaración se forma con la expedición pero sólo produce efectos con el conocimiento. El artículo siguiente sirve de perfecto complemento disponiendo que las declaraciones recepticias se entienden conocidas desde que llegan a la dirección del destinatario (fase de la recepción), salvo que él pueda probar que no la pudo conocer sin su culpa.

En nuestro Código Civil no existe una disposición de carácter general como el art. 1334 del Código italiano, que consagre la eficacia de las declaraciones recepticias a partir del conocimiento por parte del destinatario. Tan sólo existe una norma muy específica de la cual puede extraerse indirectamente que el conocimiento produce la eficacia de las declaraciones recepticias. Se trata del art. 1373, según el cual el contrato se forma en el momento y lugar en que el oferente conoce la aceptación. El sentido de este precepto no es el de regular las declaraciones recepticias, ni el de establecer su eficacia, sino el de fijar claramente el momento y lugar de formación del contrato; su fuente se encuentra inmediatamente en el primer párrafo del art. 1326 del Código italiano. Sin embargo, como la aceptación, que es una declaración recepticia, cierra el ciclo formativo del contrato, de la disposición que comentamos puede extraerse que el momento de eficacia es el del conocimiento.

En cambio el art. 1374 que establece, al igual que el Código de Italia, una presunción de conocimiento, sí tiene un alcance general que se extiende a todas las declaraciones contractuales dirigidas 
a persona determinada (recepticias). Es evidente que si en nuestro Código contraponemos el art. 1373 al 1374, notaremos que existe un vacio con respecto a este último. Para nada interesa establecer cuándo una declaración se considera conocida si antes no se da relevancia al conocimiento.

En nuestra opinión debe interpretarse, un poco por deducción del art. 1373, un poco por deducción del art. 1374 y mucho por las enseñanzas de la doctrina dominante y de la legislación comparada, que en el Perú las declaraciones recepticias, o sea, aquellas que son dirigidas a determinada persona, se forman al momento en que se expiden pero sólo producen efectos desde que llegan a conocimiento del destinatario; y, por estricta aplicación del art. 1374, debe reputarse que el destinatario se ha informado de la declaración, la ha conocido, desde que llegó a su dirección, a menos que pruebe que no le fue posible conocer la declaración por una causa que no les es imputable.

Dado el propósito limitado de este artículo, no vamos a detenernos en un análisis más riguroso de los artículos 1373 y 1374 de nuestro Código. Nos interesa, más bien, destacar que las declaraciones recepticias producen efecto desde que llegan a conocimiento (real o presunto) de su destinatario, debido a que existe un interés (normalmente en el declarante - pero no siempre sólo en él-) en que esa declaración sea conocida exclusivamente por su destinatario, interés que la ley considera digno de protección jurídica. Sin embargo, la ley no ha protegido ese interés del declarante en forma plena, interés que puede quedar afectado cuando es la recepción de la declaración la que se impide por una causa atribuible al destinatario, hipótesis que, en cambio, sí ha previsto el Código portugués en su art. 224.

La declaración no recepticia, en cambio, como no tiene un destinatario predeterminado y cualquiera o todos son los destinatarios, su existencia y eficacia tienen lugar al mismo tiempo, esto es, tan pronto como el declarante agota los medios necesarios para hacerla socialmente reconocible sin que requiera (para su eficacia) ser cotejada con otra persona. Así se establece específicamente en el art. 224 del Código portugués. 
La invitación a ofrecer consiste en la declaración que una persona (44) dirige a otra o a un grupo determinado de sujetos o al público en general, manifestando su propósito inicial de celebrar un (o varios) contrato determinado y su disposición a considerar las ofertas que a tal fin le formulen quienes accedieran a la invitación (45).

Debe indicarse, en primer término, que la invitación a ofrecer no es necesariamente una declaración al público, pues es perfectamente factible que se formule a una persona determinada (46), pero es más frecuente en la práctica -y dentro de ese ámbito suele estudiarse en la doctrina-que se realice frente a un grupo de personas o al público en general (incertam personam); es ciertamente muy generalizado su uso, sobre todo en la contratación en masa.

Parece de perogrullo indicar que la invitación a ofrecer no es una (verdadera) propuesta de contrato; ni pretende serlo porque se trata de una declaración que viene a cumplir una función diferente. Se observa que puede ocurrir que por causas de la más diversa índole, quien desea contratar, antes que hacer él mismo la propuesta, prefiere escuchar las ofertas que otros le formulen para lo cual solicita que aquellos que tengan interés en contratar con él expresen la oferta (condiciones) en base a la cual están dispuestos a hacerlo. Por eso, quien realiza la invitación no asume ningún compromiso sino que sólo da inicio a una fase de negociaciones o tratos preliminares que pueden culminar con las (o la) ofertas de los interesados.

Ejemplos de invitación a ofrecer nos proporciona en abundancia la doctrina, nutrida por una cada vez más frecuente práctica en el

(44) Debe tenerse presente que aquí puede hablarse más propiamente de "parte", desde que es una parte contratante potencial al que hace la invitación.

(45) MESSINEO, F. En: Trattato di Diritto Civil e Commerciale, diretto da Cicu e Missineo. V. XXI, II Contrato in Genere T. I. Giuffré. Milano, 1973. T.I, p. 323.

(46) SCOGNAMIGLIO, R. Dei Contratti.., Ob.Cit., pp. 187-188. 
mundo de los negocios y sobre todo en las operaciones en masa: el cartel exhibido sobre un inmueble con la indicación "se vende" 0 "se alquila"; los avisos económicos publicados en los diarios; el envío de catálogos y, en general, el contenido de las propagandas y promociones publicitarias realizadas por los medios de comunicación masiva, son los casos más frecuentes.

La invitación a ofrecer es siempre una declaración anterior a la oferta y, aunque puede asemejarse a ella, siempre adolece de alguno de los requisitos de la oferta. En primer lugar, no es frecuente que se indique todos los extremos del contrato cuya oferta se solicita, como es imprescindible en cambio para la oferta ordinaria, según ya se ha visto, pero sí deben señalarse aquellos que permitan a los terceros que reciben la invitación formular apropiadamente una oferta, empezando por la individualización del tipo de contrato que se pretende celebrar (47).

Puede ocurrir, sin embargo, que la invitación a ofrecer sí contenga todos los extremos del contrato que se pretende y a pesar de ello no sea una oferta de contrato porque, según se ha explicado, la autosuficiencia no es el único requisito de la oferta. Esto tiene lugar cuando el declarante, a pesar de haber fijado el contenido del contrato, no está dispuesto a contratar con cualquiera y desea evaluar a los posibles contratantes, por lo que no formula una oferta sino que invita a los interesados a hacerlo, reservándose el derecho de aceptar (o rechazar) las propuestas. Se comprende enseguida que aquí la declaración no se realiza con una seria intención de contratar, en el sentido que el declarante no pretende que surja el contrato con la sola declaración del (o de los) destinatario(s) de la invitación, sino que se requiere de una nueva declaración (esta vez de aceptación) a su cargo (48). Ya hemos anticipado el caso de las ofertas sin compromiso.

Como la invitación a ofrecer se sitúa dentro del ámbito de las tratativas, quien la realiza goza de plena libertad; la invitación a

(47) MICCIO, R. I Diritti di Credito. Vol. Secondo, parte II, II Contrato. UTET. Torino, 1977, p. 175.

(48) TRIMARCHI, P. Instituzioni di Diritto Privato. Sesta edizione. Giuffré Editore. Milano, 1983, p. 302. 
ofrecer no supone, pues, ninguna sujeción para el declarante ni se origina a su cargo ninguna obligación. Pero como excepción a la libertad de la que, como regla general, goza quien formula una invitación a ofrecer, el art. 1381 CC. le impone un deber, configurado como una verdadera carga, que consiste en rechazar sin demora las ofertas que se le dirijan si no estuviese de acuerdo con ellas, pues en caso contrario quedan concluidos con arreglo a las mismas los contratos correspondientes. Este es uno de los pocos casos en los que, en concordancia con el precepto excepcional que contiene el art. 142 CC., el silencio adquiere valor de declaración negocial con el efecto de una aceptación.

El segundo deber que como excepción pesa sobre quien invita a ofrecer es el que prevee el art. $1362 \mathrm{CC}$., de conducirse con arreglo al criterio de la buena fe entendida en su sentido objetivo (buena fe lealtad) porque, como se ha explicado, la invitación a ofrecer se sitúa en el ambiente de las tratativas.

\section{LA OFERTA AL PUBLICO}

Modernamente se discute si acaso puede distinguirse de la simple invitación a ofrecer la llamada oferta al público, o sea, si en ésta pude observarse la naturaleza de una verdadera oferta de contrato; también se pregunta la doctrina qué particularidades reviste la oferta al público en el supuesto que se responda afirmativamente la cuestión anterior.

El tema no sólo es relevante en sede teórica sino que también tiene alcances prácticos de indudable importancia. Sirven para corroborarlo dos casos que el comparatista Puig Brutau extrae de la jurisprudencia anglosajona para ofrecerlos como ejemplo. El primero fue ventilado en las cortes inglesas. Según una ley de ese país, la venta de productos tóxicos sólo puede hacerse legalmente con la intervención de un farmacéutico colegiado. Una adquisición de esta clase fue realizada en un autoservicio que, ciertamente, tenía contratados los servicios de un farmacéutico que acudía a la caja en los casos necesarios para que la ley fuera cumplida, por lo menos en su interpretación literal. Como es sabido, en los autoservicios los clientes tienen acceso a los estantes que exhiben la mercadería, y luego, si 
deciden comprarlos, en la caja pagan la suma total que corresponda. El farmacéutico empleado por la tienda tenía la facultad para revisar los artículos comprados e impedir la adquisición de productos cuya composición química requería una autorización especial. La asociación de farmacéuticos (cuya finalidad real era impedir que disminuyera el número de licenciados que podría encontrar empleo) alegaba que la venta quedaba perfeccionada en el acto de escoger el cliente el producto (cuya adquisición requería la intervención del profesional), con lo que estimaba que la ley quedaba vulnerada, pues al llegar el cliente a la caja ya se había realizado la adquisición. A través de esta argumentación se sostenía que la exposición de los artículos de consumo en los estantes de la tienda era una verdadera oferta al público, que se aceptaba al tomarlos el cliente para depositarlos en la correspondiente cesta. La empresa demandada replicaba, contrariamente, que la venta no quedaba perfeccionada hasta que el cliente llegaba al mostrador y el empleado de la caja podía pedir la intervención del farmacéutico (49). Como puede observarse, la demandada sostenía, en el fondo, que la exposición de las mercaderías en los estantes es una invitación a ofrecer.

El segundo caso lo toma Puig Brutau de la jurisprudencia norteamericana. El cliente de un supermercado sufrió daños al hacer explosión una botella de agua mineral cuando la tomaba de la estantería (50). Para decidir si se trataba de un caso de responsabilidad contractual o extracontractual había que determinar si, siendo la exposición de mercaderías una verdadera oferta, la aceptación se produjo al tomar el cliente la botella o si, siendo tal exposición una invitación a ofrecer, no hubo contrato al tomar la botella que en ese momento estalló.

Vemos, pues, cómo estos meros ejemplos ilustran la relevancia práctica que puede adquirir el determinar si la oferta al público es una verdadera oferta o si sólo tiene el carácter de una invitación a formularla.

(49) PUIG BRUTAU, José. Fundamentos de Derecho Civil. Bosch. Barcelona, 1978. T. II, Vol. I, p. 182.

PUIG BRUTAU, José. Ob.Cit., T. II, Vol. I, p. 184. 
Es evidente que, como ya se ha anticipado en el rubro anterior, la invitación a ofrecer no es, por definición, una verdadera oferta, pues carece de los requisitos propios de ésta. En primer término, no es por lo regular autosuficiente en el sentido ya analizado. En segundo lugar, aunque en algunos casos pueda ser autosuficiente, no se emite con seria intención de quedar vinculado por un contrato con la mera declaración de aceptación del destinatario.

En cambio, la denominada oferta al público, observémoslo desde ahora, posee todos los requisitos propios de la oferta ordinaria y precisamente la existencia o no de estos requisitos es la que nos servirá para determinar si una declaración al público en concreto es una oferta al público o sólo una invitación a ofrecer. La oferta al público, entonces, sólo difiere de la oferta ordinaria en el carácter recepticio que ésta posee. Aquella está dirigida al público o, como dice Messineo, a la generalidad de terceros (in Incertam personam), por lo que no reviste tal carácter. Hay, sin embargo, algunos, como el propio Messineo (51), que sostienen que la oferta al público es recepticia, pues siendo indeterminado el destinatario al momento en que se formula, queda determinado al momento en que la acepta. Este temperamento no puede ser compartido, como observa exactamente De la Puente, ya que si la aceptación determina la existencia del consentimiento, y por lo tanto la formación del contrato mismo, la oferta al público sería recepticia, según Messineo, por la determinación del destinatario, precisamente en el momento en que la oferta deja de tener existencia para fundirse con la aceptación, dando lugar al contrato.

Es importante entonces determinar si la ausencia del carácter recepticio, único aspecto del que adolece la oferta al público, es suficiente para hacerle perder su naturaleza de verdadera oferta y la reduce, por tanto, a una simple invitación a ofrecer. El carácter recepticio viene atribuido a la oferta por cuanto ésta cumple la función de formar el contrato conjuntamente con la aceptación. El contrato implica, por lo general, una relación personal, de modo que quien se propone celebrar un contrato debe saber con quién ha de

(51) Doctrina General del Contrato. Ediciones Jurídicas Europa-América. Buenos Aires, 1952. T. I, pag. 319. FERRI, Luigi. Ob.Cit., p. 78. 
hacerlo y tener la certeza de que contratará con quien él desea. Esto significa, según hemos tenido ocasión de explicar a propósito de las declaraciones recepticias, que si Ticio dirige una oferta a Cayo, Sempronio no puede aceptarla, y si lo hace la aceptación será ineficaz o, en el mejor de los casos, podría considerarse como una oferta de éste a aquél. La aceptación implica el ejercicio de un poder, de una facultad que se confiere con la oferta, pero sólo al destinatario. El carácter recepticio es, pues, un aspecto que se reconoce en la oferta como también en otras declaraciones-y que el derecho tutela en la medida en que responda a un interés que la ley considera, precisamente, digno de protección jurídica. Sin embargo, si el propio oferente desea conscientemente prescindir de este carácter que vendría a proteger su interés (el de conocer con quien contrata y contratar específicamente con quien él desea y no con otro) no vemos inconveniente jurídico alguno que determine que, en tal circunstancia, no exista una verdadera oferta, pues no se resiente ningún principio de derecho. A este argumento debe agregarse el que aporta Lavalle (52), según el cual debe protegerse la buena fe y la expectativa del público que este tipo de oferta pueda despertar. La evolución del comercio y de los negocios en general, así como la sociedad misma, van demandando progresivamente nuevas soluciones y nuevas figuras que el derecho debe brindarle; y es deseable que ello ocurra pues el Derecho, como instrumento al servicio del hombre, debe contribuir a esa evolución o corre peligro, en caso contrario, de resultar anacrónico.

Nuestro legislador, respondiendo a las necesidades de los nuevos tiempos, y con el loable afán de elaborar un código de avanzada, ha regulado el fenómeno de la contratación masiva y lo ha hecho fundamentalmente a través de la reglamentación de dos expresiones de ese fenómeno, que son el contrato por adhesión y el que se celebra en base a cláusulas generales de contratación. Aun cuando la forma en que se ha concebido esta regulación pueda en alguna medida criticarse sanamente (53), no puede dejar de reconocerse que el

(52) En: Código Civil y Leyes Complementarias. Director: Belluscio. Coordinador: Zannon. Astres. Buenos Aires, 1984. T.S., p. 760. También FONTANARROSA, Rodolfo. Ob.Cit., T. II, p. 68.

(53) Ver, por ejemplo, el valioso trabajo de Alfredo Bullard en Themis, Segunda Epoca, 1989. № 15, pp. 47 y sgtes. 
Código ha sido permeable a una realidad insoslayable que no podia dejar de atender. Lo curioso, sin embargo, es que habiendo reconocido y legislado el fenómeno de la contratación en masa, que tiene como una de las características fundamentales la despersonalización de los contratantes, la estandarización de las relaciones, no haya podido desprenderse de la oferta en su concepción tradicional. No resulta lógico concebir la contratación en masa si no podemos concebir la oferta también en masa; no podemos concebir la despersonalización del contrato si no concebimos también la despersonalización de la oferta, porque, precisamente, la oferta al público viene a encontrar su más natural (aunque no único) ámbito de actuación en esta esfera del contrato masivo. Es como si el legislador admitiese el contrato como expresión del moderno mundo industrial, pero exigiese para su formación un procedimiento artesanal. Esta crítica ya ha sido puesta de relieve, por lo demás, con un singular acierto, por Bullard (54).

Y es que, en la actualidad, el contrato tal como ha sido tradicionalmente concebido desarrolla todavía una función insustituible, pero paralelamente existe este nuevo fenómeno del contrato estandard; no existe inconveniente en concebir la subsistencia simultánea de una forma de oferta tradicional (recepticia) y, paralelamente, la oferta al público (no recepticia).

Por esto, nosotros consideramos que la oferta al público es una verdadera propuesta contractual. Empero, no podemos dejar de reconocer que la ausencia del carácter recepticio en este tipo de ofertas (por la circunstancia de estar dirigidas al público), origina no pocos problemas que la doctrina intenta solucionar.

En primer lugar, por público debe entenderse, según la opinión que consideramos más acertada (55), a todo el conjunto de sujetos potencialmente interesados. Este concepto puede ser en la práctica más o menos amplio, según que la oferta pueda despertar interés en todos y cada uno de los miembros de la comunidad o sólo en un sector o grupo particular de ella (por ejemplo, se ofrece un puesto de trabajo

(54) Ob.Cit., p. 54.

(55) SCOGNAMIGLIO, Renato. Commentario..., Ob. Cit., p. 191. 
para el ejercicio de una actividad profesional muy especializada). Sin embargo, entendemos con Díez-Picazo que semejante distinción no merece atención por carecer de relevancia jurídica (56).

No es inconveniente reiterar, antes de seguir adelante, que salvo el carácter recepticio del que, como ya se ha señalado, adolece la oferta al público, ésta debe reunir todos los requisitos de la oferta ordinaria que ya han sido explicados en páginas anteriores. Si tenemos esto presente podremos solucionar sin mayor difcultad algunos de los problemas que han agobiado a la doctrina, y lo que es más importante, podremos diferenciar con mayor nitidez la oferta al público de la invitación a ofrecer.

En este sentido, la oferta al público debe ser autosuficiente en los términos que ya se han dejado establecidos, de modo que cuando la oferta al público no sea completa por ausencia, por ejemplo, de la indicación del precio, debe considerarse que se trata de una invitación a ofrecer y no de una verdadera oferta (57).

Como se ha explicado, la doctrina de la oferta al público se viene desarrollando bajo el influjo del ejercicio del comercio moderno, caracterizado cada vez más por las operaciones en masa, lo que ha llevado a sostener a un autor italiano (58) que este tipo de oferta se ve con mayor claridad donde el vendedor tiene interés en incrementar su actividad, no formulando propuestas individuales, sino ofreciendo a la generalidad sus productos, de modo de poder obtener el número más elevado posible de aceptaciones y, por lo tanto, de negocios. Pero esta regla de carácter general no significa que sólo pueda considerarse como oferta al público la que tiene como sustento la contratación en masa.

La oferta al público, en efecto, puede ser plural o múltiple (en

(56) Fundamentos de Derecho Civil Patrimonial. Tecnos. Madrid, 1979. T. I, pag. 196. También SCOGNAMIGLIO, Renato. Commentario...,, Ob. Cit., p. 191.

(57) A menos que resulte aplicable el art. $1547 \mathrm{CC}$.

(58) MICCIO, Renato. Ob.Cit., Vol. II, T. II, pp. 172-173. 
serie) cuando busca obtener el mayor número de aceptaciones, y, por ende, de contratos, pero también puede ser única, esto es, destinada a la celebración de un solo contrato. Puede ocurrir, entonces, que se produzcan tanto en uno como en otro caso mayor número de aceptaciones de las que es capaz de satisfacer el proponente. En estos supuestos no falta quien pretende escapar del problema sosteniendo que allí se perfila antes que una verdadera oferta una invitación a ofrecer. El razonamiento es el siguiente:

Si Primus hace una oferta al público para la venta de zapatos, de los que sólo dispone 600 pares, y se producen 800 aceptaciones, se habrían celebrado 800 contratos y Primus estaría irremediablemente condenado a incumplir 200 contratos. En cambio, si se considera que la oferta al público realizada por Primus no es realmente una oferta sino una invitación a ofrecer, las aceptaciones del público serían realmente las ofertas, de las que Primus sólo aceptaría 600 y rechazaría el resto, con lo cual sólo se formarían los contratos que Primus puede satisfacer. Este es un ejemplo claro de cómo muchas veces el jurista, ante un problema grave de no fácil solución, prefiere eliminar a la institución afectada por el problema antes que remediarlo directamente. Es como matar al paciente a fin de eliminar la enfermedad que lo aqueja.

Con Scognamiglio compartimos la opinión de que esta tesis es inexacta y errónea, ya que la naturaleza de la oferta al público dependería de la existencia o no de más aceptantes de los que pueden ser satisfechos por el oferente, lo cual es un aspecto extrínseco y ajeno a la oferta misma y, por tanto, independiente de ella (59).

Debe ponerse de relieve, en primer lugar, que lo que preocupa a quienes así razonan no es el destinatario de la declaración, o sea el público, la masa de consumidores; lo que parece interesar es que hay que proteger al declarante, aun frente al consumidor, porque parecería que podría quedar vinculado por más contratos de los que podrá cumplir. Entonces, para tutelar a quien ofrece al público se sacrifica el interés del consumidor, pretendiendo que lo que aquél ha hecho es más bien una invitación a ofrecer. Decimos que se sacrifica el interés del consumidor porque tal solución permite a quien ha hecho una

(59) SCOGNAMIGLIO, Renato. Commentario..., Ob.Cit., p. 193 
"invitación a ofrecer" rechazar no sólo las "ofertas" de los consumidores que exceden las posibilidades de aquél, sino que incluso puede rechazar las "ofertas" que se hagan dentro del límite de la capacidad del que invita.

Así, en el ejemplo de la oferta al público de zapatos, Primus no sólo puede rechazar las ofertas que el público hace por sobre los 600 pares de zapatos de los que dispone, sino que incluso podría rechazar cualquiera de las primeras 600 ofertas que le hagan los consumidores, a pesar de disponer de la mercaderia porque, como se considera que sólo son "ofertas", él es libre de rechazarlas o aceptarlas. Y en este caso: ¿cómo se tutela al consumidor? ¿ y por qué se le ha de sacrificar frente al empresario? Claro que podría sostenerse que si se rechaza la oferta del consumidor de mala fe podría incurrirse en el supuesto de responsabilidad pre-contractual. Pero, por un lado, la responsabilidad pre-contractual y sus alcances no están suficientemente perfilados en nuestro Código y, en segundo término, aun por este camino no se evita que el consumidor se quede sin el bien 0 servicio de que se trate.

En nuestra opinión, debe considerarse que la oferta al público, cuando tiene todos los requisitos que ya se han indicado, es una auténtica propuesta contractual y así debió haberse reconocido en nuestro Código, porque no existe ninguna razón de orden teórico que sugiera lo contrario y porque, antes bien, precisamente razones de orden práctico de tutela de los consumidores y de seguridad jurídica en general, exigen que así sea.

La oferta al público encuentra su límite cuantitativo en atención al volumen o cantidad de mercadería disponible por parte del oferente, o a la potencialidad de su organización, si se trata de oferta de servicios, salvo que en la declaración se fije el límite de la oferta, en cuyo caso debe atenderse a este límite, porque lo contrario no responde a los dictados de la razón; sería absurdo suponer que un empresario, cuando ofrece al público sin indicar el límite lo hace por encima de sus posibilidades.

Es razonable, en cambio, considerar que cuando un oferente desee ofertar más allá de sus posibilidades, indique en su propia oferta cuál es el límite de ésta. El problema del límite de la oferta al 
público se reduce a una tarea de comprobación. Regresando al ejemplo propuesto, si Primus formula una oferta al público para la venta de zapatos, de los que sólo dispone 600 pares, aunque su oferta no lo exprese, debe entenderse que está formulando una oferta hasta por 600 pares de zapatos, o, si se prefiere, 600 ofertas. Si en la declaración se fija el límite, éste debe respetarse, aunque sea inferior a la capacidad del oferente y también cuando supera esa capacidad. Si Primus hace una oferta para la venta de zapatos, indicando que el límite es de 300 pares, debe regir ese límite aunque él disponga de 600 . Si se indica que el límite es de 800 , rige este límite aunque disponga sólo de 600 . Frente a una solución como ésta no puede argumentarse, como es evidente, que el oferente al público está desprotegido.

Podría, sin embargo, sostenerse que debe protegerse la buena fe de los destinatarios, quienes ignoran la capacidad del proponente, $y$ la oferta al público puede haber alentado sus expectativas que luego no se ven satisfechas cuando en la oferta no se indica límite y las aceptaciones rebazan esa capacidad. Es claro que adoptando la solución de nuestro Código y considerando a la oferta al público como una invitación a ofrecer, lejos de proteger al destinatario se le perjudica en mayor medida, como ya se ha puesto de relieve líneas arriba.

Entonces, para proteger la buena fe de los destinatarios podría pretenderse que la propia oferta al público, para tener validez, debe expresar su propio límite, y de no hacerlo no sería una oferta completa (no sería autosuficiente) y, por lo tanto, se convertiría en una invitación a ofrecer. Esta tesis es absolutamente inadmisible por dos razones. La primera es que la indicación del límite en la propia oferta en muy poco contribuye a disipar la incertidumbre del público, pues si bien es cierto que todos sabrian el límite de la oferta nadie sabría cuántos ya han aceptado y por lo tanto no se sabría si la próxima aceptación se encuentra dentro o fuera del límite indicado en la propuesta. Pero, además, en segundo lugar, pretendiendo tutelar a los destinatarios de esta manera no conseguimos sino un efecto contrario, porque justamente cuando en la oferta no se indica límite, que es cuando más debe protegerse a los destinatarios, más desprotegidos quedan al considerar que no existe oferta sino invitación a ofrecer, con lo cual se cae en el régimen que ya se ha criticado. 
En verdad, puede sostenerse que los destinatarios de una oferta al público saben o deberían racionalmente suponer que toda oferta tiene un límite, aunque éste no se indique, y que el oferente no está en aptitud de satisfacer todas las aceptaciones que potencialmente podrían tener lugar - lo contrario nos parece absurdo-, y no pueden más que someter sus expectativas a esta circunstancia aleatoria (60). Nadie puede sostener razonablemente que una oferta al público, por el hecho de no indicar límite, es infinita.

Ahora bien, no puede soslayarse que en una realidad como la nuestra en donde campea la informalidad, en donde el consumidor no es por lo general de un nivel cultural promedio, etc., se hace imprescindible algún mecanismo de tutela del destinatario de la oferta al público que se concilie, no obstante, con el interés del oferente. En tal sentido, debe partirse de la regla general de considerar que toda oferta al público, en la medida en que reúna todos los requisitos necesarios, es una auténtica oferta de contratar dirigida al público. En segundo término, si la oferta al público indica su propio límite, entonces debe estarse a dicho límite. En tercer lugar, y esto es lo importante, si la oferta no indica ningún límite debe entenderse que el límite está determinado por la capacidad del oferente pero, para proteger al destinatario, debe establecerse que el oferente debe probar que la aceptación se produjo por encima de su límite. O sea, como el oferente tiene la posibilidad de indicar explícitamente el límite de su oferta y no lo hace, pesa sobre él la carga de probar cuál era su límite $\mathrm{y}$, por tanto, que esta aceptación rebasó dicho límite y, por ello, no hay contrato. De esta manera, el aceptante no tiene que probar cuál es el límite del oferente y que su aceptación está dentro de ese límite, ya que producida la aceptación se presume (Iuris Tantum) que está dentro del límite, salvo que el oferente demuestre lo contrario.

Ahora bien, como la oferta al público - ya sea que sea en serie, ya que sea única- puede despertar interés entre múltiples destinatarios, pueden, por ello, producirse muchas aceptaciones, incluso más allá del límite del oferente. En este caso la doctrina predominante se inclina por admitir que rige aquel principio general del derecho

(60) FONTANARROSA, Rodolfo. Ob.Cit., p. 69. 
según el cual la prevalencia entre muchos sujetos que aspiran a conseguir una misma situación de ventaja se determina por el orden cronológico, y de acuerdo a esto el contrato se concluye frente al destinatario cuya aceptación llegue primero a conocimiento del proponente, si se trata de una oferta única, o frente a los destinatarios cuyas aceptaciones alcancen a cubrir el límite del oferente, tratándose de una oferta múltiple (61).

En cambio, uno de los problemas más serios en la oferta al público se produce cuando se presentan dos o más aceptaciones contemporáneas, o cuando no siéndolo no se puede comprobar un orden cronológico y no todas puedan ser atendidas porque algunas de ellas escapan al límite de la of erta. De inmediato se ensayan dos tesis distintas en la doctrina. Así, a Mirabelli le parece más justa la solución consistente en la atribución pro-parte (dividir en partes iguales) a cada uno de los aceptantes contemporáneos, siempre que el objeto sea divisible (62). Según otros autores lo más correcto es constituir una comunión de derechos respecto de todos los aceptantes contemporáneos (63). Pero, como pone de relieve Scognamiglio, estas alternativas lejos de solucionar el problema resultan muy poco adecuadas. La oferta, en efecto, al igual que cada aceptación, se emite por todo el bien o conjunto de bienes y no por parte material o alícuota de él. Cualquiera de las alternativas que hemos revisado sólo sería factible, en nuestra opinión, en la medida en que los interesados estén conformes. Si no fuera así, sólo quedarían dos posibilidades: atribuir al oferente la facultad de decidir con cuál aceptante se forma el contrato (64), lo cual — podría sostenerse - atenta contra la igual-

(61) DIEZ-PICAZO, Luis. Ob.Cit., pag. 197. SCOGNAMIGLIO, Renato. Commentario..., Ob. Cit, p. 193. MIRABELLI, Giusseppe. Ob.Cit., p. 110.

(62) MIRABELLI, Giussepe. Ob.Cit., p. 110.

(63) FRAGALI, citado por Scognamiglio. Commentario..., Ob. Cit., p. 194. También MESSINEO, $I l$ Contrato in Genere..., Ob. Cit. Tomo I, pp. 320-321.

(64) Conf. SCOGNAMIGLIO, Renato. Commentario..., Ob. Cit., p. 194. 
dad de los aceptantes, o considerar que en semejante circunstancia la propuesta caduca (65).

Renato Miccio ha encontrado también serias dificultades en aquellas ofertas al público que tienden a la conclusión de un contrato en el cual el proponente ofrece una compensación a aquél del público que, aceptando la propuesta, se comprometa a efectuar una determinada prestación (66). En este caso se tiene, en primer lugar, una limitación cuantitativa de la colectividad a la cual la propuesta es dirigida, porque no se trata de adquirir un bien de normal consumo, sino de cumplir una actividad que por razones de capacidad profesional, de organización empresarial u otra, no todos están en aptitud de desarrollar. El proponente, al decir de Miccio, no es animado por el fin de tener el mayor número de aceptantes posibles, como en la hipótesis más corriente, sino por aquélla, opuesta, de poder escoger entre una multiplicidad de personas que declaran aceptar, el contratante que más le conviene (67). La finalidad de estas declaraciones es satisfacer el interés del sujeto de encontrar más fácilmente el contratante más idóneo, de manera que a través de una declaración al público se persigue obtener varios potenciales aceptantes para evaluarlos en concreto (por sus cualidades, experiencia, la confianza que ofrece, etc.), y decidir si se contrata con él, o escoger cual de todos satisface mejor las expectativas del interesado.

En la hipótesis propuesta por Miccio no puede, por ello, encontrarse una verdadera oferta al público, y la doctrina predominante se inclina por observar, con toda razón, que tales declaraciones son propiamente invitaciones a ofrecer (68). Contra esta opinión mayoritaria, Miccio argumenta que esta clase de declaraciones al público, en las que el proponente se reserva una facultad de elección basada en la evaluación personal del aceptante, son verdaderas ofertas al público. Según el aludido autor, en estos supuestos se debe atribuir

(65) Conf. MIRABELLI, Giusseppe. Ob.Cit., p. 110.

(66) MICCIO, Renato. Ob. Cit. T. II, Vol. II, p. 173.

(67) MICCIO, Renato. Ob.Cit. T. II, Vol. II, p. 173.

(68) SCOGNAMIGLio, Renato. Dei Contratti.., Ob. Cit., p. 192. 
al oferente un poder de elección justificado por la calidad del aceptante, o mejor, por las garantías que éste ofrece para conseguir el resultado deseado por el proponente (69). Miccio ofrece el ejemplo de la persona que desea emprender la búsqueda de un pariente o un amigo perdido en la montaña, para lo cual formula una oferta entre el público en una estación alpina. La oferta viene aceptada primero por uno de los tantos apasionados de la montaña y luego por un guía profesional muy conocido por su grado de habilidad. Si no se acepta esta facultad de elección, concluye Miccio, el proponente debería entender que ha contratado con el primer aceptante, poniendo así en grave peligro la vida del extraviado, mientras el guía profesional podría conducir una búsqueda mucho más eficaz.

Esta facultad de elección que se atribuye al oferente en casos como el propuesto tiene sustento, según el jurista italiano, en el aspecto intrínseco y sustancial que caracteriza a la obligación con prestación de hacer, según el cual la calidad de la prestación reviste un carácter determinante que influye sobre los términos mismos de la aceptación, y puede determinar, incluso, que no se considere como verdadera y propia la aceptación, lo que legitimaría al proponente a rechazarla por no considerarla conforme a la propuesta (70).

Al margen de la validez del aspecto subjetivo (intrínseco y sustancial) que según Miccio caracteriza la obligación con prestación de hacer, no creemos que esta elaboración teórica sea suficiente para sostener la validez de la oferta al público como verdadera oferta en todos aquellos casos en que, como el del ejemplo, se trate o no de obligaciones con prestación de hacer, pueda considerarse que el oferente tiene una facultad de elección respecto de los eventuales aceptantes, consistente en contratar o no y, en caso afirmativo, escoger con cuál de los aceptantes quedará finalmente concluido el contrato. El problema que observa Miccio no se limita, pues, a los casos de ofertas al público que implican una obligación con prestación de hacer, sino en todos aquellos supuestos en los que el oferente se ha reservado expresa o implícitamente una facultad de elegir al contratante entre todos los aceptantes.

(69) MICCIO, Renato. Ob.Cit. T. II, Vol. II, p. 173.

(70) MICCIO, Renato. Ob.Cit. Vol. II, T. II, pp. 174-175. 
Líneas arriba hemos dejado establecido que, salvo el carácter recepticio, la oferta al público debe reunir los demás requisitos propios de la oferta ordinaria, principio que nos debe servir de guía para establecer con nitidez la verdadera naturaleza jurídica del tipo de oferta al público (llamémosle así por el momento) que ahora analizamos. Hemos señalado también, en su portunidad, que uno de los requisitos de la oferta ordinaria es la seria intención de obligarse a contratar que anima a quien la formula, de tal suerte que se declara con el propósito de que quede formado el contrato por la sola aceptación del destinatario. En las ofertas al público del tipo que ahora estamos tratando, el proponente no tiene el propósito de contratar tan pronto como una aceptación se produzca sino que, contrariamente, desea poder evaluar a los posibles aceptantes y contratar con quien puede satisfacer mejor su interés. La ausencia de este requisito es suficiente, en nuestra opinión, para privar a este tipo de ofertas al público de su naturaleza de verdaderas propuestas contractuales, por lo que, como ya hemos adelantado, nos adherimos plenamente a quienes ven en ellas meras invitaciones a ofrecer, figura que entendemos se encuentra más acorde con su naturaleza y con el propósito práctico del declarante (71). Sin embargo, no podemos dejar de advertir que la ausencia de este requisito debe resultar objetivamente de los propios términos de la declaración o de otras circunstancias, de modo que los destinatarios puedan percatarse de ello; si esto no fuera así, habría que tutelar la confianza del público y entender que existe una oferta al público (principio de la confianza).

Desde 1984, y por primera vez, nuestro Código se ocupa del problema de la oferta al público. Ya se ha expuesto al inicio de este trabajo que el primer párrafo del art. 1388 le atribuye, con carácter general, la naturaleza de una invitación a ofrecer, inscribiéndose dentro de la tesis según la cual la oferta al público no es una verdadera oferta. Con ello el legislador, que ha pretendido elaborar el código más moderno, desatiende las enseñanzas de la doctrina más autorizada y descarta los principios expuestos. Sin embargo, no puede dejar de admitir nuestro Código la existencia de verdaderas ofertas dirigidas al público, por lo que en el segundo párrafo de dicho

(71) SCOGNAMIGLIO, Renato. Commentario..., Ob.Cit., p. 192. MIRABELLI, Op.Cit., p. 109. 
artículo se admite, por excepción, que valen como tal las ofertas al público cuando el proponente indique claramente que la suya tiene el carácter obligatorio de una oferta.

No creemos que la solución adoptada por nuestro legislador sea la más acertada. A ella resultan, pues, aplicables las críticas que se han expuesto en las lineas que anteceden y sobre todo la de haber dejado absolutamente desprotegido al consumidor. La solución adoptada por el legislador parece sustentada en que, faltando en la oferta al público el carácter recepticio de una oferta ordinaria, aquélla no puede tener la naturaleza juridica de verdadera propuesta. AriasSchreiber (71a), autor de la respectiva ponencia en el seno de la Comisión Reformadora, sostiene, en efecto, que "... tratándose de una declaración en la que el declarante no sabe quien la recibirá y ni siquiera si alguien la recibirá, aparece claro que la propuesta al público no se identifica con la oferta contractual cuya única razón es motivar la formación del contrato...". Ya hemos visto líneas arriba que la sola ausencia del carácter recepticio no es suficiente para desnaturalizar la oferta al público. Pero por lo menos Arias-Schreiber, aunque equivocado en nuestro concepto, es consecuente con su propia línea de pensamiento, ya que el precepto originalmente no admitía la oferta al público ni siquiera por vía de excepción.

Ignoramos, por otro lado, los motivos en que se inspiró el legislador para agregar el segundo párrafo del artículo que se comenta; el artículo original del anteproyecto (art. 30) (72) no consignaba el citado segundo párrafo (que apareció después en el proyecto definitivo de la Comisión Reformadora); la exposición de motivos que sustentaba dicho anteproyecto se ha reproducido textualmente en la Exposición de Motivos y Comentarios al Código Civil (72a), y en ella no encontramos ninguna explicación del legislador. Sería deseable que en la Exposición de Motivos "Oficial", que viene publicándose fraccio-

(71a) En: Código Civil, T. IV: Exposición de Motivos y Comentarios, p. 49.

(72) Proyectos y Anteproyectos de la Reforma del Código Civil. Pontificia Universidad Católica del Perú. Fondo Editorial. Lima, 1980, T. II, pp. 425 y 426 .

(72a) Código Civil, VI, Exposición de Motivos y Comentarios. Pp. 49-50. 
nadamente y cuya parte pertinente no se ha hecho pública a la fecha en que se escriben estas líneas, se explique la ratio del segundo párrafo (73).

Lo cierto es que el mentado segundo párrafo de nuestro art. 1388 , que tiene carácter de excepción, tampoco consagra un precepto conveniente. Según él, sólo vale como oferta al público aquella en la que el proponente indica claramente que tiene carácter obligatorio. Sin embargo, si en opinión del legislador lo que quita la naturaleza de oferta a la propuesta al público es la ausencia del carácter recepticio, aun cuando se la emita como obligatoria sigue careciendo de tal carácter y no vemos cómo, entonces, sí vale como verdadera oferta contractual. Pero, además, no sólo tiene que ser obligatoria la oferta (efecto que desgraciadamente tiene en nuestro Derecho toda propuesta contractual -salvo ciertas excepciones- por imperio del art. 1382 del Código), sino que, además, el proponente tiene que indicarlo claramente.

Tratando de encontrar un sentido lógico al párrafo que comentamos, podría sostenerse que el legislador, permeable a los argumentos que exhiben los detractores de la oferta al público, ha pretendido cautelar las expectativas del público (destinatarios), evitando que sea inducido a error y que luego se discuta si la declaración era una oferta al público o una invitación a ofrecer; exigiendo, para este fin, que su naturaleza de verdadera oferta resulte con claridad de los propios términos de ella, de modo que se emita concurriendo aquel requisito que debe acompañar siempre a toda oferta contractual, consistente en la seria intención de vincularse que debe animar al proponente, según se ha explicado en su lugar al analizar dicho requisito.

Pero para ello no era necesario exigir que el proponente declare

(73) Tampoco existe ninguna referencia a la segunda parte del artículo 1388 del Código Civil en la obra Exégesis (ARIAS-SCHREIBER, Max. Studium. Lima, 1986. T. I, pp. 140-141) que, en opinión de su autor, es también una exposición de motivos del Código, sin valor oficial (Ob.Cit., pag. 8), ya que el comentario pertinente al artículo que nos ocupa es el mismo que sustentó originalmente su anteproyecto, salvo el último párrafo que se refiere a otro aspecto. 
que su oferta es obligatoria (lo que significa que es vinculante, esto es, irrevocable); hubiera bastado exigir, en todo caso, una declaración del proponente en el sentido de que su propuesta al público tiene la naturaleza de verdadera oferta. Por otra parte, son las reglas de interpretación las que deben indicar si una declaración es o no una oferta. Otra posibilidad es que el legislador haya pretendido que al indicarse en la oferta que ésta es obligatoria, ya el oferente quedaba en la situación de tener que satisfacer a todos los aceptantes, o sea, que se formaban tantos contratos como aceptaciones se produzcan sin tener en cuenta el límite de la oferta. Es claro que esta posibilidad es menos razonable y no creemos que haya estado en la mens legis. Como se sabe, indicar que la oferta es "obligatoria" sólo significa que la oferta no puede revocarse, pero en ningún caso la oferta se transforma en infinita, con lo cual no se soluciona el problema del límite de la oferta. Pero, además, como en toda oferta, nada debería impedir que la oferta al público se emita con el carácter de revocable, sin que pierda su naturaleza, si reúne a la vez todos los requisitos que le son propios. Por lo general, con mayor razón que en los casos de ofertas ordinarias, en la oferta al público es no sólo aconsejable sino conveniente admitir la revocabilidad (74), ya que normalmente se le utiliza, en el ámbito mercantil, para operaciones en masa o en serie.

Cabe preguntarse a estas alturas de la exposición cuál de los verdaderos problemas existentes én torno a la oferta al público han quedado solucionados con la fórmula legislativa. Imaginemos qué ocurriría si en nuestro medio una cadena de establecimientos que vende aparatos electrónicos formula una declaración al público que contiene todos los requisitos de una oferta, pero no se expresa que tiene el carácter obligatorio de una oferta. Aplicando el art. 1388 a esta declaración, a pesar de ser una oferta, tiene el valor de una invitación a ofrecer, con lo cual este establecimiento comercial puede negarse a contratar con quien desee, aunque al hacerlo disponga aún de una cantidad apreciable de mercadería. Puede negarse a contratar incluso a pesar de haber fijado un límite en su oferta y encontrarse aún por debajo de ese límite. Llegando al extremo, podría negarse a contratar con cada uno de los interesados.

(74) FONTANARROSA, Rodolfo. Ob.Cit. T. II, p. 70. 
Si en la declaración se agrega esta frase mágica que alude a que la oferta al público tiene el carácter obligatorio de una oferta, entonces la ley le reconoce a esa declaración el valor de una verdadera oferta. Y nos preguntamos, ¿es que esa frase mágica convierte a la oferta en infinita de manera que la cadena comercial puede recibir aceptaciones ilimitadas? Y si en la oferta se ha indicado el límite, ¿debe éste respetarse? Y si hay varios consumidores que aceptan contratar respecto del último bien ¿se encuentra la solución en la ley? La respuesta a todas estas interrogantes lamentablemente no está en el Código. El único efecto que puede tener esta frase exigida por la ley es que la oferta al público sea irrevocable, lo cual, por lo demás, no era necesario ya que por mandato del art. 1382, y salvo las excepciones que ese artículo contempla, en el Perú la oferta es irrevocable. Con esto, por otra parte, se ha eliminado absolutamente la posibilidad de que en el Perú se puedan hacer ofertas al público que sean revocables.

En el caso de que en un futuro se legisle en forma apropiada la oferta al público y se admita, ya sea con carácter general o por excepción su revocabilidad, debe establecerse que, para proteger las expectativas de los destinatarios y por la propia naturaleza de este tipo de oferta, la revocación debe realizarse por los mismos medios por los que se ha hecho pública la oferta $u$ otros equivalentes, con el objeto de hacer conocible con la misma amplitud a los destinatarios de la oferta la revocación de la misma (75).

\section{EL PLAZO DE LA OFERTA AL PUBLICO}

Una mención final merece el problema vinculado con el plazo de la oferta al público. Como es sabido, el oferente puede expresar en su oferta del plazo durante el cual aquélla estará vigente, plazo que

(75) FERRI, Luigi. Ob.Cit., p. 78. SCOGNAMIGLIO, Renato. Commentario..., Ob. Cit., p. 196. MIRABELLI, Giusseppe. Ob.Cit., p. 111. SACCO, RODOLFO. En: Trattato di Diritto Privato. UTET. Torino, 1983. Vol. 10, Tomo Secondo, p. 78. DIEZ-PICAZO, Luis. Ob.Cit., p. 197. TRABUCCNI, Alberto. Instituciones del Derecho Civil. Revuista de Derecho Privado. Madrid, 1967. Trad. Luis Martínez-Calcerrada. Vol. II, p. 171, etc. 
puede ser determinado o determinable (76). En uno u otro caso no hay todavía problema porque se sabe, ya sea directamente, ya en forma indirecta, el instante en que por la expiración del plazo la oferta se extingue. Como la aceptación debe llegar al oferente dentro del plazo fijado por éste (art. 1375 CC.), se trata tan sólo de una tarea de comprobación sobre si el plazo había o no llegado a su término cuando fue conocida la aceptación.

En cambio, el problema sí se presenta cuando en la oferta no se ha fijado ningún plazo o cuando se ha fijado uno en tal forma impreciso que no es posible determinarlo. Ambos supuestos (la oferta sin plazo fijado y la oferta con plazo indeterminable) deben ser equiparados en su tratamiento porque en ambos es imposible saber mediante la simple interpretación del contenido de la oferta, el lapso durante el cual ella estará vigente. En estos casos no es posible efectuar la simple labor de comprobación de la que hablamos líneas arriba, si no hallamos primero, de alguna manera, ese plazo dentro del cual debe llegar la aceptación a conocimiento del oferente. Precisamente para suplir la deficiencia de la oferta cuando no se indica plazo o aquél es indeterminable, el Código proporciona dos fórmulas que están contenidas en los incisos $1^{\circ}$ y $2^{\circ}$ del art. 1385 y que se aplican a la oferta que se hace entre quienes están en comunicación inmediata y entre quienes no lo están, respectivamente.

Para la primera hipótesis el plazo es sumamente breve porque la oferta se extingue si no fue seguidamente aceptada. "Seguidamente" significa inmediatamente, al momento, en el instante. No es propósito de este trabajo hacer una exégesis de estos preceptos, de manera que con cargo a abundar en un futuro diremos ahora, sólo muy de paso, que la interpretación no puede ser literal a ultranza, de manera que "seguidamente" significa, según nuestro parecer, que el destinatario dispone del mínimo plazo que sea razonable entender necesario para efectuar una reflexión elemental acerca del contrato propuesto y emitir la aceptación. Entender que "seguidamente" significa que la oferta y la aceptación deben sucederse sin solución de continuidad, llevaría sin duda alguna a un absurdo. En caso de disconformidad entre las partes sobre la oportunidad de la acepta-

(76) Vid. DE LA PUENTE, Manuel. Ob.Cit. T. I, p. 183 y sgtes. 
ción, por tratarse de una apreciación subjetiva, la extensión del plazo deberá ser decidida por el juez sobre la base del criterio indicado.

El segundo supuesto contempla el caso de la oferta que se hace entre quienes no están en comunicación inmediata. El plazo de la oferta para esta hipótesis se determina en función del plazo que toma el medio de comunicación utilizado por el oferente al efectuar su oferta. Por ejemplo, si Ticio desde Arequipa envía una oferta por correo a Cayo que domicilia en Lima, y lo que toma la comunicación por correo entre Arequipa y Lima son 20 días, entonces el plazo de la oferta de Ticio es de 20 días.

La necesidad de un plazo legal supletorio (77) no requiere demostración. Por lo general los actos, derechos, y, en general, las relaciones jurídicas, son temporales y sólo excepcionalmente perpetuas o vitalicias. Como la oferta no es un supuesto de excepción, es necesaria una disposición que permita establecer su término cuando no lo ha establecido el propio autor. Además, es preciso tener presente que la regla del art. $1382 \mathrm{CC}$. determina que la oferta sea naturalmente irrevocable, lo cual justifica en mayor medida una norma que establezca el tiempo durante el cual el oferente permanecerá vinculado a su declaración.

Ahora bien, los incisos $1^{\circ}$ y $2^{\circ}$ del art. 1385 CC. que, como se ha indicado, establecen supletoriamente el plazo de la oferta, no pueden aplicarse al caso de la oferta al público. En efecto, la oferta al público se hace, en la inmensa mayoría de los casos, de manera que entre el oferente y el público destinatario no existe comunicación inmediata. Por eso queda excluido el inciso primero. El inciso segundo establece una fórmula que tampoco es aplicable a la oferta al público. Considérese que la oferta al público se hace por medio de carteles exhibidos

(77) Debe aclararse que nosotros no avalamos las fórmulas que la ley ha establecido para determinar supletoriamente el plazo de la oferta, las cuales son muy poco apropiadas. No obstante, el análisis del tratamiento legal del plazo de la oferta en general excede el ámbito de este trabajo, por lo que sólo nos concentramos en el plazo de la oferta al público. Las nociones generales que estamos dando son imprescindibles para entender este problema. 
en lugares abiertos al público, o por medio de diarios, revistas, publicaciones televisivas $y$, en general, a través de medios de comunicación masiva. ¿Cómo podría aplicarse la regla del segundo inciso del art. 1385? Imagínese - para poner el caso más absurdo-que se hace una oferta al público por televisión. ¿Cuál es el plazo de esa oferta? El oferente tendría que esperar tan sólo el tiempo que tardaría la aceptación en llegarle por televisión.

Este vacío legal debe cubrirse atendiendo a la función que cumple la oferta y de acuerdo con las circunstancias del caso. Si fuera una oferta para contratar en masa, o sea una oferta formulada por un empresario, creemos que lo razonable es remitirse a la costumbre y usos del tráfico. Si la oferta no es de este tipo (Ticio hace una oferta al público para vender su casa), debe considerarse sometida al plazo mínimo indispensable para reflexionar sobre ella y eventualmente aceptarla.

Por último, dado que por razones de espacio no podemos extendernos más, simplemente nos limitamos a exponer que la misma preocupación en cuanto al plazo nos suscita el caso de la invitación a ofrecer. Es obvio que la invitación a ofrecer en cuanto no vincula a quien la hace, parece no requerir de un plazo. Pero no debe olvidarse que el art. 1381 impone una carga a quien formula una invitación a ofrecer, que consiste en tener que rechazar sin demora las ofertas que se le hagan pues, en caso contrario, quedan celebrados los contratos correspondientes. No ha establecido el Código una norma que indique durante cuánto tiempo pesa esta carga en el declarante en el caso en que éste no haya fijado uri plazo. La solución debe orientarse por la vía de considerar que tal carga sólo rige por el plazo que indiquen los usos, o en todo caso, un plazo razonable. No creemos que pueda considerarse una carga perpetua. 